\title{
Do the Bugs in Your Gut Eat Your Memories? Relationship between Gut Microbiota and Alzheimer's Disease
}

\author{
Emily M. Borsom, Keehoon Lee ${ }^{+} \mathbb{D}$ and Emily K. Cope ${ }^{*,+}$ \\ The Pathogen and Microbiome Institute, Center for Applied Microbiome Science, Northern Arizona University, \\ Flagstaff, AZ 86011, USA; emb366@nau.edu (E.M.B.); Keehoon.lee@nau.edu (K.L.) \\ * Correspondence: Emily.Cope@nau.edu; Tel.: +1-928-523-6004 \\ + Co-senior author.
}

Received: 2 October 2020; Accepted: 31 October 2020; Published: 3 November 2020

\begin{abstract}
The human microbiota is composed of trillions of microbial cells inhabiting the oral cavity, skin, gastrointestinal (GI) tract, airways, and reproductive organs. The gut microbiota is composed of dynamic communities of microorganisms that communicate bidirectionally with the brain via cytokines, neurotransmitters, hormones, and secondary metabolites, known as the gut microbiota-brain axis. The gut microbiota-brain axis is suspected to be involved in the development of neurological diseases, including Alzheimer's disease (AD), Parkinson's disease, and Autism Spectrum Disorder. $\mathrm{AD}$ is an irreversible, neurodegenerative disease of the central nervous system (CNS), characterized by amyloid- $\beta$ plaques, neurofibrillary tangles, and neuroinflammation. Microglia and astrocytes, the resident immune cells of the CNS, play an integral role in AD development, as neuroinflammation is a driving factor of disease severity. The gut microbiota-brain axis is a novel target for Alzheimer's disease therapeutics to modulate critical neuroimmune and metabolic pathways. Potential therapeutics include probiotics, prebiotics, fecal microbiota transplantation, and dietary intervention. This review summarizes our current understanding of the role of the gut microbiota-brain axis and neuroinflammation in the onset and development of Alzheimer's disease, limitations of current research, and potential for gut microbiota-brain axis targeted therapies.
\end{abstract}

Keywords: microbiome; gut microbiota-brain axis; Alzheimer's disease; neuroinflammation; microglia; astrocytes

\section{Introduction}

The human microbiota, the aggregate of all bacterial, viral, fungal, and archaeal cells that inhabit the human body, consists of $1-1.5 \times$ more microbial cells than human cells $\left(\sim 10^{14}\right)$ [1]. The microbiome, or the collective genomes of the resident microbes, resides throughout the entire human body, including the skin, oral cavity, respiratory tracts, vaginal cavity, and the gastrointestinal (GI) tract [2]. Recent studies of the human microbiome demonstrate a myriad of roles that these microbes play in host health, including host immune function [3,4], protection against pathogen colonization [5], and host metabolism [6]. Perturbations to normal gut microbiome functions are associated with a variety of diseases, including GI, autoimmune, neurological, and metabolic diseases [7]. The GI tract houses about $70 \%$ of the human microbiota and comprises Firmicutes, Bacteroidetes, Actinobacteria, Proteobacteria, and Verrucomicrobia [8]. These microbes aid in digestion [6], vitamin synthesis [9], and development of the nervous, endocrine, and immune system [3,4]. Members of the genera Bacteroides, Prevotella, and Lactobacillus produce B vitamins which play important roles in the host immune regulation [10]. The development of the immune system is influenced by the gut microbiome, for instance, a study by Atarashi et al. demonstrated that oral inoculation of Clostridium strains in 
germ-free mice induced colonic CD4+ T regulatory cells and reduced colitis [11]. Gut microbes are able to ferment indigestible carbohydrates, producing short chain fatty acids (SCFA) as a byproduct, and thereby promote maturation of the immune system, including colonic regulatory $\mathrm{T}$ cells [12] and bone marrow hematopoiesis of new circulating monocytes and dendritic cells $[13,14]$. In the GI tract, dysbiosis of the microbial communities can lead to overgrowth of pathogenic bacteria and a decrease in the integrity of the intestinal barrier, allowing proinflammatory molecules to circulate throughout the bloodstream [15]. For example, Ruminococcus gnavus, a common gut pathogen in Crohn's disease patients, utilizes mucin as a carbon source, directly breaking down the gut mucosal barrier and producing proinflammatory cytokines, including Tumor necrosis factor (TNF)- $\alpha$ [16].

The endocrine, neural, metabolic, and immune mechanisms that comprise the gut microbiota-brain axis contribute significantly to overall host health [17]. For instance, decreased alpha diversity in humans is correlated with decreased systemic estrogens. Depleted systemic estrogens are linked to cognitive decline, memory loss, and reduced fine motor skills $[18,19]$. Another key player in the gut microbiota-brain axis is the vagus nerve, which allows for direct communication via neurotransmitters between the CNS and the enteric nervous system (ENS) [20]. As an example, the gut bacteria Lactobacillus rhamnosus can regulate GABA receptors in mice, therefore reducing depressive behaviors via the vagus nerve [21]. Severing the vagus nerve reversed this outcome, negating the beneficial effects of L. rhamnosus in mitigating depressive behavior. Additionally, secondary metabolites and cytokines produced by the host-microbial interactions in the gut can cross the intestinal barrier and travel through the blood to induce systemic inflammation [2]. One study found increased levels of the plasma cytokines Interleukin (IL)-2, IL-1 $\beta$, and Interferon (IFN)- $\gamma$ in Ldlr-/- mice, an atherosclerosis mouse model, which were colonized with the proinflammatory gut microbiota from Casp1-/- mice, a knockout inflammatory mouse model, via fecal microbiota transplants. These findings suggest that the dysbiotic gut microbiota of the Casp1-/- mice shifted the gut microbiota of FMT treated Ldlr-/- mice. This shift led to a decrease in short chain fatty acids (SCFA) and an increase in the nuclear factor kappa-B (NF- $\mathrm{kB}$ ) activity in immune cells, thereby increasing the production of proinflammatory cytokines [2,22].

The role of the gut microbiota-brain axis has been implicated in many neurological disorders and diseases, including multiple sclerosis, gliomas, Parkinson's disease, and Alzheimer's disease (AD) [23]. In non-AD dementia, there was a lower relative abundance of Bacteroides compared to the gut microbiome of cognitively non-impaired subjects, which is the opposite pattern of what is observed in the AD gut microbiome [24]. Another study analyzed and compared the fecal microbiome and metabolites of patients with and without dementia, and the gut microbiota-associated metabolite of dementia patients was distinct from non-dementia patients [25]. For example, high phenol and p-cresol were observed in patients with dementia, which induces an increase in fecal ammonia and increases the risk of dementia. Conversely, in people without dementia, high fecal lactic acid was observed which was associated with a low risk of dementia [25]. Vascular cognitive impairment (VCI), a common cause of dementia, may be mediated with metabolites produced by gut microbiota. For example, lipopolysaccharide (LPS) and trimethylamine-N-oxide (TMAO) from gut microbiota can contribute to the increased intestinal epithelial permeability that leads to immune responses associated with VCI [26].

Several studies have demonstrated that celiac disease $(C D)$ is associated with neurological disease development $[27,28]$. CD is an autoimmune disease caused by inability to digest gluten in the small intestine. Due to intestinal epithelial dysfunction caused by $C D$, immunotoxic gluten peptide is introduced into the circulatory system and passes through the BBB, causing neuroinflammation. $C D$ also decreases the expression of PPAR- $\gamma$, which plays a role in modulating inflammation. Decreased PPAR- $\gamma$ is associated with dysbiosis of the gut microbiome and an increase in factors related to AD development such as elevated LPS, pro-inflammatory cytokines, and bacterial metabolites. One study demonstrated that CD-induced changes in the gut microbiome and neurological disease development can be improved through a gluten-free diet (GFD). Not only did GFD reduce the amount 
of neuroinflammation, but it also correlated with an increase in the expression of PPAR- $\gamma$ and gut microbiome health [27]. In addition, Transcranial magnetic stimulation (TMS), a non-invasive brain stimulation technique, enables early diagnosis of "hyperexcitable celiac brain" that often appears before dementia in $\mathrm{CD}$ patients even before any onset of clear symptoms, so that these patients can be prescribed a GFD to prevent neurodegeneration that can lead to dementia as early as possible $[29,30]$.

In this review, we present an up-to-date, comprehensive evaluation of the field of gut microbiome research in Alzheimer's disease, with a unique perspective on the potential role of the gut microbiome in neuroinflammation. We also summarize a potential mechanistic pathway describing a hypothesized role for LPS in AD pathologies. As Hippocrates once said, "All disease begins in the gut" [31]. Could this statement hold the truth, even after 2500 years? In this review, we will discuss the current understanding of the role of the gut microbiota-brain axis in $\mathrm{AD}$ and provide commentary on potential mechanisms for $\mathrm{AD}$ pathogenesis.

\section{Methodology}

Search terms to identify appropriate literature for this review using Google Scholar include, but are not limited to, "Alzheimer's disease", "gut microbiota", "gut microbiota-brain axis", in combination with "microglia", "astrocytes", "LPS", and "neuroinflammation". This review provides a current, comprehensive overview of the gut microbiota brain axis in $\mathrm{AD}$, with emphasis on modern molecular techniques, gut microbiota-induced neuroimmune pathways, and uncovering potential therapeutics. Primary studies that led to novel insights on the gut microbiome and AD in preclinical murine models and human $\mathrm{AD}$ participants were included in this literature review.

\section{Characterization of Alzheimer's Disease}

AD was first identified by psychiatrist and neuropathologist, Alois Alzheimer, in 1906. After observing plaques and neurofibrillary tangles in the brain histology of a patient who suffered from memory loss, aggression, confusion, and paranoia, he presented his findings at the 37th Meeting of South-West German Psychiatrists. Shortly after, the disease characterized by Alzheimer was coined with the name "Alzheimer's disease" by his colleague, Emil Kraepelin [32]. Today, Alzheimer's disease (AD) is the most common cause of dementia, affecting 5.8 million people in the United States alone. The prevalence of Alzheimer's disease is predicted to rise to 13.8 million in the United States by 2050 [33]. Apolipoprotein E (APOE) genotype is recognized as the strongest genetic risk factor for the development of AD. The APOE protein is involved in several biochemical regulatory processes, including immunoregulation, neuroinflammation, and neuroprotection. APOE exists in three isoforms, although APOE4 prevails as the strongest predictor of dementia. The prevailing hypothesis is the cascade hypothesis, which states that amyloid- $\beta$ plaque deposition leads to intracellular neurofibrillary tangles caused by hyperphosphorylation of the protein tau and disintegration of the microtubules in neurons, resulting in loss of neuronal function [34]. These two hallmark pathologies, extracellular amyloid- $\beta$ plaques and intracellular neurofibrillary tau tangles, are present in the hippocampus and prefrontal cortex, and result in loss of neuronal function and cognitive impairment [35]. Amyloid plaques form when the amyloid precursor protein (APP) is sequentially cleaved by endogenous proteases, $\beta$-protease and $\gamma$-protease. This cleavage event renders peptides ranging in length and solubility, yet $A \beta-42$ tends to form soluble fibrils, and is the predominant species observed in the brain of severe AD patients $[36,37]$. Amyloidosis may begin as early as $10-20$ years before cognitive decline or AD symptoms become apparent [38]. In addition to plaques and tangles, neuroinflammation is increasingly recognized as central to disease progression; current studies have identified both microglia and astrocyte induced inflammation as a key pathological feature of AD [39]. While not yet considered a core pathology for diagnosis, neuroinflammation remains a driving feature in $\mathrm{AD}$ pathogenesis [40]. 


\section{Techniques for Microbiome Analysis}

Advances in the fields of sequencing and bioinformatics allow for increasingly accurate analysis of microbial communities and their role in human health. The field of microbiome sequencing has been dominated by marker gene sequencing. For bacteria, 16S rRNA gene is a widely used marker gene, and fungi can be identified using marker sequences on the 18S rRNA gene or the ITS (internal transcribed spacer) region. Selection of the $16 \mathrm{~S}$ rRNA gene was based on the presence of nine highly variable regions within the gene, allowing for bacterial taxonomic classification, that are flanked by conserved regions that allow for primer design [41]. The ITS regions are situated between the $18 \mathrm{~S}$ rRNA gene and the 5.8S rRNA gene (ITS1) and the 5.8S rRNA gene and the 28S rRNA gene (ITS2). ITS1 and ITS2 have high evolutionary rates, allowing for greater taxonomic resolution than is possible with 18S rRNA gene sequencing [42]. However, for those who are interested in species- and strain-level taxonomic resolution, shallow shotgun metagenomic sequencing (SSMS) is becoming increasingly popular [43]. While SSMA does not provide the depth of taxonomic and functional resolution that deep shotgun metagenomic sequencing does, it is relatively low cost compared to deep shotgun metagenomics, and therefore more feasible to apply in large-scale studies [43].

Functional and mechanistic aspects of the microbiome's integral role in health or disease can be assessed by integrating a multi'omics approach including deep shotgun metagenomics, transcriptomics, and metabolomics. As discussed above, deep shotgun metagenomic sequencing will provide strain-level and functional information encoded in the DNA content of a microbiome. In shotgun metagenomics, all of the DNA present in a sample is sequenced with minimal PCR amplification bias. This allows characterization of the species and encoded genes in a wide array of microorganisms, including fungi, bacteria, archaea, parasites, and DNA viruses. Although metagenomic sequencing can characterize the functional potential of a microbial community, this DNA-based approach is unable to determine differences in gene expression in a given environment. Transcriptomics, or RNA-seq, can be used to evaluate changes in gene expression. Finally, we can identify and quantify primary and secondary metabolites (e.g., short chain fatty acids) produced by the host and microbiota using metabolomics. Metabolomics can lead to a better understanding of microbial communication and microbial community involvement in metabolic pathways [44]. Understanding community composition is essential for microbiome studies; however, an integrated, multi-omics approach is critical to elucidate the microbial taxa and mechanisms essential to host health and disease.

\section{Gut Microbiota-Brain Axis in Alzheimer's Disease}

Although amyloid plaques and tau tangles are thought to be central to AD, over 2000 clinical trials targeting plaques, tangles, neurotransmitters, and other related mechanisms have failed to successfully treat $\mathrm{AD}$ [45]. However, the bidirectional communication between the GI tract and the central nervous system (CNS) via immune, endocrine, neural, and metabolic pathways, known collectively as the gut microbiota-brain axis, has recently been hypothesized to contribute to AD etiology and pathogenesis $[23,46]$. The human gut microbiome influences neuroinflammation in AD through the production of proinflammatory cytokines and bacterial metabolites that can enter circulation and reach the brain to act on neuronal immune cell populations [47]. Proinflammatory cytokines involved in AD pathogenesis include IL-1 $\beta$, IL-6, IL-18, TNF- $\alpha$, and IFN- $\gamma$ [48]. Overexpression of IL- 1 has been shown to favor plaque deposition in vivo and in vitro [49], while upregulation of IL-6 is associated with hyperphosphorylation of tau, leading to neuronal degradation [49,50]. Both $A \beta$ plaques and neurofibrillary tangles are co-localized with activated glial cells in the CNS, suggesting gliosis plays a major role in AD pathogenesis and neuroinflammation [51]. In addition to cytokines, bacterial metabolites, including trimethylamine $N$-oxide (TMAO) and SCFAs may play a role in the development of or protection against $\mathrm{AD}$ pathologies. TMAO, a gut microbiome-produced metabolite previously linked to cardiovascular disease [52], is increased in the cerebrospinal fluid of AD patients and is directly correlated to CSF tau biomarkers, suggesting a role in brain aging and cognitive decline [53]. On the other hand, SCFAs, particularly valeric, butyric, and propionic acid, have the potential to 
ameliorate amyloidosis by interfering with $\mathrm{A} \beta 1-40$ and $\mathrm{A} \beta 1-42$ peptide interactions, thereby preventing conversion to neurotoxic $A \beta$ plaque formation [54]. We expand on each of these topics, below.

\section{Enteric Nervous System: Vagus Nerve}

The enteric nervous system (ENS) is the largest part of the autonomic nervous system, composed of over 100 trillion neurons that function independently from the CNS [55]. The neural circuits that make up the ENS control local motor function and blood flow, fluid secretions and transports, and regulate immune and endocrine functions [56]. As a major component of the gut microbiota-brain axis, the vagus nerve directly connects the gut to the brain and spinal cord [17]. The vagus nerve mediates signaling pathways for satiety, stress, and mood via microbial and neural signaling [57]. Therefore, perturbations to the nerve disturb the gut-microbiota brain axis, leading to gastrointestinal diseases, including irritable bowel syndrome [58]. However, the vagus nerve is also able to receive input from the gut microbiota and transfer this information to the central nervous system [59]. To illustrate, enteroendocrine cells (EECs), making up 1\% of gut epithelial cells, release 5-HT (serotonin precursor) in response to chemical or mechanical stimulation, which stimulates 5-HT3 receptors on the vagus nerve. Stimulation of these receptors controls physiological responses including peristalsis, gut motility, and other visceral functions [60].

In terms of treatment options, the vagus nerve remains a viable target for $\mathrm{AD}$ treatment. Clinical trials targeting the vagus nerve through stimulation have shown some cognitive improvement in AD patients up to one year post-treatment [61,62]. Vagus nerve stimulation (VNS) has also shown sustained, long term cognitive improvement in refractory depression patients [63]. A more recent study in transgenic APP/PS1 mice reversed morphological signs of aging and activation in 12 month mice using non-invasive vagus nerve stimulation [64]. However, the use of VNS as a therapeutic for $\mathrm{AD}$ is still a novel idea and requires further investigation of the mechanisms involved.

\section{Gut Microbiota Composition and Diversity in Individuals with AD}

The hypothesis that members of the gut microbiota contribute to AD onset and progression via the gut microbiota-brain axis has emerged in the past five years. However, few studies have been completed in the clinical setting. To our knowledge, five studies have characterized the gut microbiota composition in human $\mathrm{AD}$ patients compared to age-matched, non-AD controls, all showing an altered bacterial microbiota composition in AD patients. A cross sectional study of the gut microbiota composition in patients selected for their APOE genotype demonstrated that APOE4 carriers had decreased abundance of butyrate producing gut bacteria, including Clostridium, and lower levels of fecal SCFAs compared to other APOE genotypes, indicating a relationship between $A P O E$ isoforms and gut microbiota compositions [65]. The second study conducted in AD patients demonstrated a decrease in the phyla Firmicutes and an increase in Bacteroidetes, as well as an increase in the genus Blautia in AD patients. They also observed decreased alpha (within sample) diversity in AD patients. Additionally, they observed correlations between CSF markers of AD and relative abundance of taxa; a significant positive correlation was demonstrated between the genus Bacteroides and CSF YK-40, a marker of astroglia and microglia activation. These findings suggest an increase in Bacteroides may be linked to increased neuroinflammation [66]. We discuss the potential mechanisms below. The other three studies demonstrate a gut microbiota composition with decreased abundance of SCFA-producing bacteria and increased abundance of proinflammatory bacteria when comparing AD patients to non-dementia, aged-matched controls [67-69]. Taxa identified in the individual studies can be found in Table 1.

Alterations in the bacterial gut microbiota have been observed in AD patients, indicating a potential role for gut microbes in AD. Three of the five studies in human patients showed significant changes in the genus Bacteroides, although the directionality of this change, whether Bacteroides relative abundance increased or decreased, differed (Table 1). Future research to determine whether environmental factors independent of $\mathrm{AD}$ pathologies cause the observed shifts in the gut microbiome are necessary. 
For example, dietary changes as a person progresses through dementia, the influence of medications on the composition of the gut microbiota in $\mathrm{AD}$, decreased body mass, and overall well-being should be considered as potential mediators of the gut microbiota composition and diversity. Finally, changes in the microbiota may extend beyond the gut. The post mortem brain of AD patients has a higher bacterial burden when compared to age matched controls, consisting mostly of Actinobacteria, particularly Propionibacterium acnes [70]. Additionally, mice infected orally with Porphyromonas gingivalis exhibited brain colonization associated with increased amyloidosis [71]. These findings provide intriguing evidence for translocation of microbes from the gut, suggesting that microbes have the ability to cross both a dysfunctional gut epithelial barrier and blood brain barrier. Further studies are required to determine whether microbial translocation from other body sites to the brain occurs in AD.

Table 1. Alterations in gut microbiota composition in humans and transgenic mice without intervention.

\begin{tabular}{cccc}
\hline Species & Increased Abundance & Decreased Abundance & Citation \\
\hline Human & $\begin{array}{c}\text { g.Blautia, } \\
\text { g.Alistipes, g.Bacteroides }\end{array}$ & $\begin{array}{c}\text { g.Turicibacter, } \\
\text { g.Clostridium, g.Dialister }\end{array}$ & Vogt et al. [66] \\
\hline Human & $\begin{array}{c}\text { g.Gammaproteobacteria, } \\
\text { g.Enterobacteriales and } \\
\text { f.Enterobacteriaceae }\end{array}$ & $\begin{array}{c}\text { g.Ruminococcus } \\
\text { f.Clostridiaceae, } \\
\text { f.Lachnospiraceae }\end{array}$ & Liu et al. [67] \\
Human & g.Ruminococcus, g.Subdoligranulum & $\begin{array}{c}\text { f.Lachnospiraceae, } \\
\text { g.Lachnoclostridium, } \\
\text { g.Bacteroides }\end{array}$ & Zhuang [68] \\
Human & g.Bacteroides, g.Alistipes, g.Odoribacter & $\begin{array}{c}\text { g.Butyrivibrio, } \\
\text { g.Eubacterium, } \\
\text { g.Lachnoclostridium, }\end{array}$ & Haran et al. [69] \\
\hline APP/PS1 & $\begin{array}{l}\text { g.Desulfovibrio, g.Akkermansia, } \\
\text { f.Lachnospiraceae, g.Ruminococcus }\end{array}$ & g.Alistiples & Chen et al. [72] \\
\hline
\end{tabular}

\section{Gut Microbiota Composition and Diversity in Murine Models of Key AD Pathologies}

Transgenic mouse models of key AD pathologies are an essential tool in mechanistic studies and drug discovery with the potential for translational treatments in clinical trials [32]. Numerous studies have shown that transgenic murine models have unique gut microbiota compositions when compared to the gut microbiota compositions of wild-type mice of the same genetic background or compared to transgenic mice with the wild-type allele $[35,72,73]$. Parikh and colleagues assessed changes in the gut microbiota composition of 5xFAD mice, a transgenic familial model of plaque deposition that was homozygous for APOE2, APOE3, or APOE4. Significant changes observed in the gut microbiota between genotypes regardless of $5 x F A D$ mutations suggests a relationship between the gut microbiota composition and APOE isoforms [74]. In a study by Chen and colleagues, transgenic APP/PS1 mice, a model bearing the mutations in transgenes for APP and PSEN1 resulting in A $\beta$ plaque deposition, demonstrated altered microbiota preceding amyloidosis and microgliosis, suggesting a role of the gut microbiota in AD pathogenesis (Table 1, [72]). In 5xFAD mice, which express human APP and PSEN1 transgenes with five AD-linked mutations, leading to rapid development of amyloidosis, an increase in the phylum Firmicutes and a decrease in the phylum Bacteroidetes was observed at nine weeks. More specifically, Clostridium leptum was increased in 5xFAD mice, a common gut bacterium associated with gut inflammation [73]. When raised germ-free, APP/PS1 mice exhibited significantly reduced amyloidosis and microgliosis, suggesting that in absence of the gut microbiota, AD pathologies are less severe and supports the hypothesis that the gut microbiota plays a critical role in AD pathologies [75].

To better understand the mechanisms behind these alterations in the gut microbiota composition of transgenic models of AD pathologies, including amyloid deposition and neurofibrillary tangles, manipulation of the gut microbiota allows for uncovering potential processes involved in AD development. Manipulation of the gut microbiota through prebiotics, probiotics, and fecal microbiota 
transplants are potential therapeutic options for AD and have been explored in preclinical murine models of AD pathologies (Table 2). Bonfili and colleagues administered SLAB51, a mixture of nine live bacterial strains, to 3xTg-AD mice, a transgenic model exhibiting $A \beta$ plaques and tau tangles. SLAB51 treated mice reduced proinflammatory cytokine production (IL- $1 \beta$, IFN- $\gamma$, and TNF- $\alpha$ ) and cerebral $A \beta$, while simultaneously increasing SCFA production and cognitive function. However, there were no significant changes in microbial taxa, but rather an overall shift of the gut microbiota following SLAB51 treatment [76]. Another study employed the prebiotic, fructooligosaccharides (FOS), to modulate the gut microbiota in APP/PS1 mice. FOS treated mice exhibited decreased A $\beta$ deposition, increased cognitive function and synaptic plasticity, and reversed altered gut microbiota in APP/PS1 mice to more closely resemble wildtype mice [77]. A study on the impact of high-fat diet in 3xTg-AD mice showed increased Rikenellaceae and Lachnospiraceae and decreased Bifidobacteriaceae and Lactobacillaceae in the colon when compared to normal fed 3xTg-AD mice [78]. Wang and colleagues treated 5xFAD mice with sodium oligomannate (GV-971), an algae-based drug, which remodeled the gut microbiota, and reduced M1 microglia activation and neuroinflammation. These findings suggest gut microbiota derived metabolites including the amino acids phenylalanine and isoleucine invoke neuroinflammation. In the same study, 5xFAD mice were co-housed with wildtype mice from birth to seven months. The results showed the gut microbiota of the 5xFAD and wildtype had shifted to resemble each other, and co-housed wild type mice had increased infiltrating Th1 cells in the brain, indicating the role of the gut microbiota composition in changes immune cell expression and neuroinflammation [35]. FMT treatment of APP/PS1 with wildtype mouse feces alleviated cognitive decline, $\mathrm{A} \beta$ accumulation, and Tau hyperphosphorylation through reversing alterations in the gut microbiota of APP/PS1 mice. To illustrate, before the treatment, APP/PS1 mice were enriched with Proteobacteria and Verrucomicrobia; however, post-treatment, the abundance of Proteobacteria and Verrucomicrobia had decreased, while Bacteroidetes increased [79].

Table 2. Alterations in gut microbiota composition in transgenic mice after the intervention.

\begin{tabular}{ccccc}
\hline Species & Increased Abundance & $\begin{array}{c}\text { Decreased } \\
\text { Abundance }\end{array}$ & Intervention & Citation \\
\hline 3xTg-AD & g.Bifidobacterium & o.Campylobacterales & SLAB51 probiotic & Bonfili et al. [76] \\
\hline APP/PS1 & g.Lactobacillus & g.Helicobacter & FOS supplement & Sun et al. [77] \\
\hline 3xTg-AD & $\begin{array}{c}\text { f. Rikenellaceae, } \\
\text { f.Lachnospiraceae, } \\
\text { f.Enterococaceae and f.S24.7 }\end{array}$ & $\begin{array}{c}\text { g.Bifidobacterium, } \\
\text { g.Lactobacillus }\end{array}$ & Fatty diet & Sanguinetti et al. [78] \\
\hline
\end{tabular}

\section{Potential Role of the Gut Microbiome in Neuroinflammation in AD}

Neuroinflammation has recently been recognized as a key feature of AD. Neuroinflammation is the body's combined biochemical and cellular responses of all resident glial cells to injury or infection of the nervous system and neurodegenerative diseases [80]. To prevent damage to the CNS, resident immune cells recognize any disturbances to homeostasis of the brain and respond with production of cytokines and chemokines to mediate tissue damage [81]. In healthy adults, aging leads to changes in the immune system, resulting in what is often termed "inflammaging", or chronic, low-grade inflammation due to aging [82]. Microglia increase responsiveness to inflammatory stimuli with aging, while astrocytes act to preserve neuroinflammation [83]. The main driver of age-related neuroinflammation in Alzheimer's patients is reactive gliosis, or the activation of the glial cells of the CNS to prevent and repair tissue damage [84]. Age-related changes in microglial activation result in changes in gene expression, rendering dysmorphic microglia with morphological alterations, including abnormalities in cytoplasm and fragmented processes [85]. These changes may be related to the gut microbiome. A study in germ-free mice demonstrated increased abundance of Desulfovibrio, a gut bacterium associated with intestinal inflammation, after transfer of an aged mouse gut microbiota [86]. 
These findings suggest unique gut microbiota compositions in aging mice may be associated with chronic, low grade inflammation.

While neuroinflammation is initially a reparative mechanism to prevent damage, the neuroinflammatory response in $\mathrm{AD}$ patients shifts from neuroprotective to neurotoxic, damaging tissue in the CNS [51]. Neuroinflammation remains constant, with consistently high levels of cytokines and chemokines, and increased neuronal cell death [87]. This chronic inflammation is associated with shorter and fewer microglial processes, reducing mobility, thereby inhibiting their ability to survey and monitor their environment $[64,88]$. The cytokines produced by microgliosis and astrogliosis worsen tauopathy and drive sustained neuroinflammation [89].

\subsection{Neuroinflammation: Microglial Activation and the Gut Microbiome}

Many diseases of the CNS that are linked to the gut microbiome, such as AD, Parkinson's Disease, Multiple Sclerosis, and Autism Spectrum Disorder, simultaneously involve dysfunctional microglia [90]. Microglia are the main immune cell in the brain, colonizing the brain early in development, and maintaining homeostasis during aging [91]. As the specialized macrophages of the CNS, microglia function as phagocytes to clear bacteria, cellular debris, and A $\beta$ peptides [92,93]. Microglia work to monitor their microenvironment through constant extension and retraction of their highly motile processes [94]. The acute neuroinflammatory response induced by A $\beta$ peptides is a self-limiting, neuroprotective immune response [72]. However, aging microglia are ineffective at phagocytosing the neurotoxic $\mathrm{A} \beta$ plaques present in $\mathrm{AD}$ [95]. Instead, microglia are activated by aggregated $\mathrm{A} \beta$ plaques, driving a chronic neuroinflammatory response [38].

Microglia receive input from not only the brain but also the GI tract via the vagus nerve [57]. When the vagus nerve senses a change in inflammation and proinflammatory cytokine production in the GI tract, afferent fibers relay this information to the brain and influence neuroinflammation [59]. However, electrical stimulation of the vagus nerve attenuates neuroinflammation induced by peripheral LPS (lipopolysaccharide), a component of the Gram-negative bacterial cell envelope that can be released upon cell lysis. In one study, C57BL/6 mice were challenged with peripheral LPS and subjected to vagus nerve stimulation (VNS). VNS in the presence of LPS resulted in an increase of IL-6, IL-1 $\beta$, and TNF- $\alpha$ [96]. A study by Huffman and colleagues challenged C57BL6/J mice with Escherichia coli derived LPS to induce neuroinflammation. Percutaneous VNS stimulation reduced neuroinflammation, restored LPS-induced cognitive decline, and modulated microglial activity [97]. Another study using external, non-invasive VNS in 12-month old APP/PS1 transgenic AD mice illustrated a shift from neurodestructive to neuroprotective microglia phenotypes [64]. Taken together, these studies demonstrate that LPS is a potent stimulator of microglia via the vagus nerve, and vagal nerve stimulation may reverse neurotoxic microgliosis.

Microglia polarization is determined by a complex group of activation processes by different stimuli in the CNS, resulting in microglia polarization [98]. When an injury is present, microglia are capable of cytotoxic response and immune regulation, to resolve the damages [99]. Differentiated microglia polarize to two main phenotypes: pro-inflammatory or M1, and neuroprotective or M2 [100]. Microglia phenotype is based on their activation pathways that communicate via environmental signals to alter gene expression and cellular metabolism [101]. Classical activation by lipopolysaccharide (LPS) and IFN- $\gamma$ polarize microglia cells to an M1 state, inducing production of pro-inflammatory cytokines, including TNF- $\alpha$, IL-1 $\beta$, IL-12 [102,103]. Alternative activation by IL-4 and IL-13 polarize microglial cells to an M2 state, inducing production of anti-inflammatory cytokines, including IL-4, IL-13, IL-10, and TGF- $\beta$ [102]. Thus, microbial signals may be critical in M1/M2 polarization and therefore neurological health.

Microglia and the gut microbiota communicate via the gut microbiota-brain axis, regulating immune homeostasis. Wang and colleagues demonstrated M1 polarized neuroinflammation in 5xFAD mice is a result of abnormal production of amino acids, including phenylalanine and isoleucine, by the gut microbiota. Increased M1 activation as a result of crosstalk with Th1 cells infiltrating the 
CNS induced pathological neuroinflammation and cognitive decline [35]. Gut microbiota alterations may also affect microglia activation by controlling maturation and function. In this study, adult germ-free mice, lacking microbiota signaling, have distinct microglia with changes in density and morphology [57]. Furthermore, a study on critical hypertension indicated the influence of microglia dysfunction and neuroinflammation on the microbial communities in the gut. In this study, inhibition of microglia activation led to changes in the phylum Proteobacteria, suggesting that microglia activity plays a role in modulating the gut microbiota composition [104].

\subsection{Neuroinflammation: Astrocyte Activation and Gut Microbiome}

Astrocytes are specialized resident glial cells in the CNS, and responsible for protection, support of neurons, and overall homeostasis [105]. When damage occurs to the CNS, astrocytes drive an inflammatory process called astrogliosis [106]. Astrocytes function in A $\beta$ clearance and blood brain barrier (BBB) integrity maintenance through production of cytokines and chemokines, including IL-1, IL-6, and TNF- $\alpha$, to signal a pro-inflammatory innate immune response $[35,107,108]$. Making up about $50 \%$ of human brain mass, astrocytes play critical roles in neurodegenerative disorders and cognitive decline, including AD [109].

Neuroinflammation in AD is exacerbated by dysfunction of astrocytes, resulting in decreased BBB integrity and recruitment of immune cells from the blood. Astrocyte dysfunction can lead to deposition of $A \beta$ peptides in the brain and results in endothelial cell damage and leakage of the blood brain barrier [110]. In one study, patients with mild cognitive impairment and early AD underwent dynamic contrast material-enhanced magnetic resonance (MR) imaging to analyze BBB leakage, demonstrating cognitive decline is directly related to severe leakage [111]. Furthermore, cytokines are able to both cross the blood brain barrier and damage the blood brain barrier by increasing permeability without entering the brain [112]. IL-1 $\beta$, IL-6, and TNF- $\alpha$ have been shown to modify functional activity of the BBB and can be selectively transported across the BBB [113]. A $\beta$ adhesion to microglia induces proinflammatory gene expression, producing IL- $1 \beta$ and TNF- $\alpha$, thereby activating astrogliosis and amplifying the neuroinflammatory response. Increased proinflammatory cytokine production and neuroinflammation eventually lead to tau hyperphosphorylation and neuronal loss [114,115]. Recent studies have shown that gut microbiome impacts the function of astrocytes. The microbial product, LPS, potentiates the production of inflammatory mediators from astrocytes, leading to neurodegeneration [116]. LPS has been used in many studies to induce microgliosis, astrogliosis, and neuronal apoptosis [117-119]. Increases in the relative abundance of Nitriliruptor, Youngiibacter, Burkholderia, and Desulfovibrio, in children with an autism spectrum disorder, correlate with astrocyte activation [120]. Additionally, SCFA production by the gut microbiota may inhibit astrocyte activation. A study by Liu and colleagues demonstrated acetate, propionate, and butyrate, common SCFAs produced by the gut microbiota, suppress LPS and proinflammatory cytokine production through inhibition of the NF- $\mathrm{KB}$ pathway in vitro [121]. However, increased Lachnospiraceae, Ruminococcaceae, and Prevotellaceae in the GI tract of NLRP3-deficient mice ameliorated astrocyte dysfunction and reduced depressive-like behaviors [122]. These findings suggest astrocytes may be a potential therapeutic target for neurological disorders, including $\mathrm{AD}$, associated with astrocyte activation and dysfunction.

\section{Microbial Etiology Hypothesis in AD}

Changes in gut microbiota composition and diversity during aging can drive age-associated inflammation; recent studies in Drosophila [123] and in murine models [124,125] suggest that alterations to the gut microbiota in late life drive increased intestinal permeability and increased systemic inflammatory markers. Since neuroinflammation is a key feature of Alzheimer's disease (AD), understanding the aging gut microbiome is critical to understanding AD progression. Mechanistically, bacteria in the GI tract can produce a significant amount of amyloids (aggregated, insoluble proteins exhibiting $\beta$-pleated sheet structures) can contribute to $A \beta$ plaque formation and increase the risk for AD development [126-128]. Microbiome-derived functional amyloids have been described in the 
multiple microbial taxa, including Saccharomyces cerevisiae, and broadly in the family Enterobacteriaceae. Escherichia coli extracellular amyloids known as curli fibers help to facilitate attachment to surfaces and protection against host defenses [129-132]. Both curli fibers from E. coli and sup35 from S. cerevisiae were capable of enhancing amyloid aggregation and amyloidosis in a murine model of experimental amyloidosis, indicating that microbial-derived amyloids may have prion-like properties [133]. In another study, amyloids derived from three species of Gram-negative bacteria (E. coli, Salmonella typhimurium, and Citrobacter koseri could induce polymerization of amyloid aggregates across species in vitro, again demonstrating the potential for microbiome-derived amyloids to contribute to amyloidosis in AD [134]. Microbial amyloids may also enhance the immune response to endogenous amyloids, contributing to neuroinflammation. Microbial amyloids are sensed by Toll-like receptor 2 (TLR2), which can induce expression of many of the neuropathological features observed in AD, discussed above. Curli from S. typhimurium was sufficient to induce IL-17A, IL-22, and IL-6 in the intestinal epithelium, and these responses were blunted in TLR-2 deficient mice [135]. However, these findings must be placed into the context of a healthy or dysbiotic microbiome; another study found that commensal-derived amyloids may help to maintain the epithelial barrier and induce anti-inflammatory IL-10 expression in the gut [136]. The altered microbiome composition observed in human and preclinical models may lead to impaired epithelial barrier, allowing microbiome-derived amyloids to translocate, cross-seed with endogenous peptides, or activate a neuropathological immune response.

The endotoxin hypothesis of neurodegeneration states that the endotoxin, or LPS, found in the outer membrane in all Gram-negative bacteria, crosses the blood brain barrier to induce neuroinflammation and neurodegeneration. The proposed pathway begins with a GI infection, or perhaps an increase in absolute abundance of a Gram-negative gut microbes, results in increased circulating endotoxins, which cross the BBB, leading to chronic neuroinflammation and finally, neurodegeneration [137,138]. Dysbiosis of the gut microbiota resulting in enrichment of Gram-negative bacteria in the gut microbiota is associated with increased LPS-driven inflammation [139]. Notably, Bacteroides fragilis, a known LPS-producing gut bacterium, is hypothesized to contribute to inflammatory signaling in AD patients via the NF-kB pathway [140].

Peripheral LPS may contribute to neuroinflammation and $A \beta$ plaque deposition in the brain (summarized in Figure 1). LPS in the gut activates the enteric nervous system, and can stimulate production of the proinflammatory cytokines TNF- $\alpha$, IL-1 $\beta$, and IL- 6 , which are secreted in the gut and can travel to the periphery [141]. More specifically, activation of the ENS leads to TNF- $\alpha$ induced inhibition and production of IL-6 in the GI tract or ENS cells in vitro, a known inflammatory cytokine in AD [142]. Inflammation of the GI tract increased intestinal permeability to recruit immune cells from circulation, however also allowing inflammatory bacterial components to cross the barrier into the peripheral circulatory system, eliciting systemic inflammation [87]. Pathogenic microbial metabolites, proinflammatory cytokines and other molecules produced by the gut microbiota, including LPS, are associated with neuronal death and neuroinflammation [143]. TLR-4, a known LPS receptor, is localized on microglia, astrocytes, and neurons, and plays a role in both cell survival and death [144]. The activation of TLR-4 on microglia and other neural cells leads to activation of the NF- $\mathrm{kB}$ pathway, thereby increasing the production of cytokines and A $\beta$ deposition. Additionally, TLR- 4 is expressed in vagal afferent fibers, which allow the vagus nerve to sense LPS and activate the brain [59]. In rats, IP injection of LPS resulted in increased expression of IL-6, IL-1 $\beta$, and TNF- $\alpha$ in the brain, and LPS co-associated A $\beta$ plaque deposition [145]. The role of LPS in the development of AD is reviewed in [146].

A considerable amount of research points towards an infectious etiology of AD. Inflammation is an essential process in healing damaged tissue and fighting off infection, however, chronic inflammation leads to permanent damage. Studies have noted bacteria, viruses, protozoa, and fungi as potential agents in systemic infections related to AD [147]. Injection of Helicobacter pylori, an opportunistic pathogen of the GI tract, induced memory impairment and $A \beta$ plaque deposition through increased 
gene expression of presenilin- 1 in rats and in vitro. In the same study, injection of Escherichia coli, another common gut pathogen, demonstrated no change in cognitive impairment or plaque deposition [148]. Furthermore, in another study, different regions of the brain in AD patients, including the frontal cortex and hippocampus, had evidence of Candida spp. cells and hyphae, while control patients showed no signs of fungal cells or hyphae, providing intriguing evidence for existing fungal infections in AD brains [149]. Moreover, there is evidence to suggest fungal infections in the brain can be accompanied by bacterial infections, demonstrating polymicrobial infections of the brain in $\mathrm{AD}$ may contribute to pathogenesis and neuroinflammation [150]. Taken together, these studies suggest translocation of microbes into the brain and chronic microbial infection may play a role in neuroinflammation and AD neuropathologies.

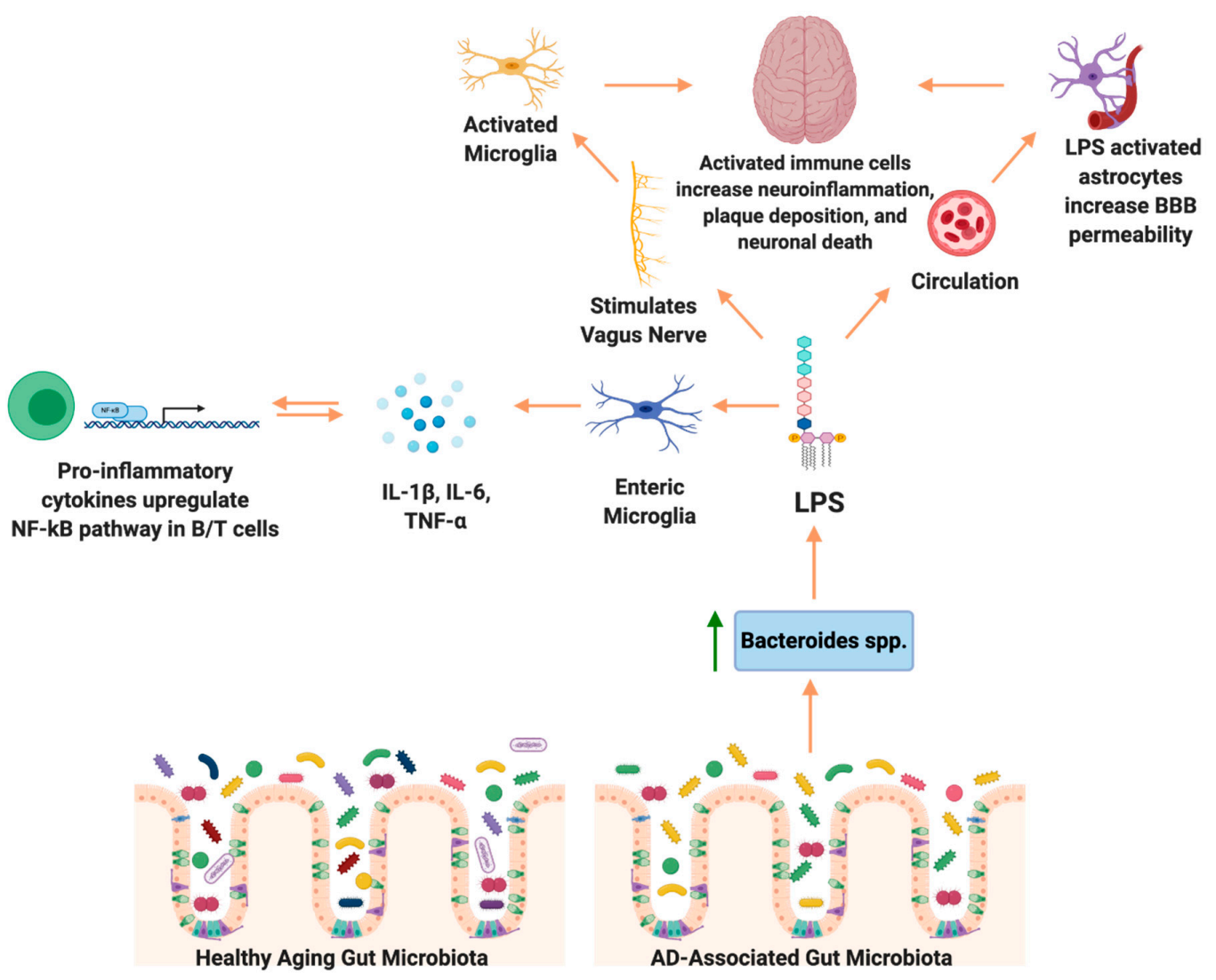

Figure 1. Proposed mechanism of lipopolysaccharide (LPS)-induced neuropathologies in Alzheimer's disease (AD). AD-associated microbiome composition has increased abundance of lipopolysaccharide (LPS) producing bacteria, including Bacteroides. LPS stimulates enteric microglia to produce Interleukin (IL)-1 $\beta$, IL-6, and Tumor necrosis factor (TNF)- $\alpha$, which induces the nuclear factor kappa-B (NF- $\mathrm{B}$ ) pathway, therefore upregulating expression of proinflammatory cytokines. Similarly, LPS stimulates the vagus nerve, activating microglia in the brain, thereby promoting neuroinflammation. LPS is able to translocate from the gastrointestinal tract to the circulatory system and stimulate astrocytes. The reduction in blood brain barrier (BBB) integrity allows LPS to cross the BBB and further promote inflammation in the brain.

\section{Potential for Microbiome-Based Therapeutics}

The gut microbiota-brain axis remains a target for future therapeutics for AD. Immunotherapy [151] and gut microbiota-targeted therapy [17] are among the many potential therapeutic targets for $\mathrm{AD}$. Immunotherapy targets include the anti- $\mathrm{A} \beta$ and anti-tau target antibodies, $\mathrm{A} \beta$ vaccines, and cytokine inhibition [151-153]. Passive immunization of naturally occurring autoantibodies injected into APPSwe mice, a single transgenic model for amyloidosis, reduced toxic $\mathrm{A} \beta$ oligomers, and improved cognitive 
function [154]. 3xTg-AD mice immunized with active, full length DNA A $\beta 42$ demonstrated reduced plaque deposition and tauopathy [155]. LPS-treated 3xTg-AD mice injected with TNF inhibitor XENP345, a TNF cytokine inhibitor, reduced accumulation of 6E10 immunoactive protein, which contains amyloid precursor protein fragments, therefore preventing pre-amyloidosis pathologies [156]. Neuroimmune therapeutics targeting reduction of $A \beta$ plaques and neurofibrillary tangles continue to evolve as understanding of disease pathologies becomes more clear. Due to the complexities involved in disease progression, combinatorial immunotherapy may hold promise to a future of immunotherapeutics for AD [157].

Potential gut microbiota target therapies include prebiotic/probiotic supplementation and fecal microbiota transplantation to restore gut microbiota to a diverse, healthy microenvironment [158]. In 3xTg-AD mice, oral probiotic supplementation reduced $A \beta$ burden and hyperphosphorylated tau aggregates through gut microbiota manipulation [159]. A study using E4FAD mice, a model for late onset $\mathrm{AD}$, demonstrated that supplementation with the prebiotic inulin increased SCFA's and reduced neuroinflammation [160]. Early probiotic trials in patients with AD or mild cognitive impairment remain promising with results showing improved cognitive function, suggesting the involvement of the gut microbiota brain axis [161,162]. Despite the numerous studies on transgenic mice modeling AD pathologies, few translational studies in AD patients have been published. A case study of an 82 year old man with AD followed the patient over a six month period following an FMT treatment for a Clostridioides difficile infection. The patient showed significant improvement on his Mini-Mental State Examination and scored in the normal cognition range at two and six months post treatment. However, this was a case study, and a clinical trial of the effects of FMT on AD patients through modulation of the gut microbiota-brain axis is warranted [163].

Another method of gut microbiota targeted therapy is through dietary intervention. Numerous epidemiological evidences have demonstrated a link between diet, gut microbiota, and human health [164-166]. However, only recently have the mechanisms linking diet and human health been uncovered. Diet and lifestyle are closely related to cardiovascular and metabolic diseases, which are connected to neurological disorders. For example, insulin resistance and high plasma homocysteine levels, which are indicators of metabolic syndrome (Mets), play a major role in cerebral physiology and morphology, amyloid- $\beta$ deposition, and neurological plaque accumulation [167]. In addition, several studies have demonstrated that healthy diet patterns such as Mediterranean diet (MeDi), dietary approach to stop hypertension (DASH), and Mediterranean-DASH diet intervention for neurodegenerative delay (MIND) are effective in reducing dementia and AD risk [168-171]. Brain glucose uptake is impaired in $\mathrm{AD}$, possibly due to a loss of synapses and neuronal dysfunction [172]. If deprived of glucose, the primary energy source, the brain can switch to utilization of ketones (specifically $\beta$-hydroxybutyrate ( $\beta$-HB) and acetoacetate (AcAc); $[173,174])$. Interestingly, brain ketone uptake remains normal in AD patients $[175,176]$. Thus, several studies and review articles have assessed the potentially beneficial effect of a ketogenic diet in AD [177-180]. Indeed, a systematic review of randomized clinical trials evaluating ketogenic and non-ketogenic dietary interventions in participants with mild cognitive impairment $(\mathrm{MCI})$ and $\mathrm{AD}$ showed promising results from the studies included, despite heterogeneity in study design, dietary compliance, and participants [181].

The gut microbiome is greatly affected by these dietary interventions. Changes in the composition of the intestinal microbiota caused by diet affect the various metabolites they produce, and these changes can regulate the host immune response in a beneficial way and maintain the health of the nervous system. For example, a ketogenic diet increased relative abundances of potentially beneficial bacteria (Akkermansia and Lactobacillus) compared to mice fed a control diet. This correlated with enhanced neurovascular function, and amyloid- $\beta$ clearance which was associated with reduction in mTOR expression and increased endothelial nitric oxide synthase (eNOS) protein expression [182]. In a study of patients with mild cognitive impairment, gut microbiota composition is associated with cognitive impairment. A modified Mediterranean-ketogenic diet (MMKD) regulated gut microbiome composition and production of metabolites such as SCFA, which were associated with improvement of 
AD symptoms $[183,184]$. These studies suggest the modification of gut microbiome through dietary intervention can be a strong candidate for future AD therapy. Future studies focused on the gut microbiota-brain axis as a therapeutic utilizing a multi-omics approach, which is crucial for uncovering the role of the gut microbiota-brain axis in $\mathrm{AD}$ and the development of therapeutics.

\section{Limitations of Current Research}

Current research on the gut microbiota-brain axis in Alzheimer's disease is based mostly on compositional microbiome data using $16 \mathrm{~S}$ rRNA marker gene sequencing. Few studies have evaluated the role of fungal microbiota in the gut, though recent work has demonstrated a critical role of fungal communities in health and development of peripheral organs through sensing of fungi by gut-resident immune cells, such as mononuclear phagocytes [185]. While this approach has laid the foundation for the field, the use of transcriptomics, metagenomics, and metabolomics will be necessary to uncover the complex set of mechanisms involved in the gut microbiota-brain axis. There are a limited number of studies in human AD patients, as highlighted by the minimal studies cited in this review, and the studies in human $\mathrm{AD}$ to date have been observational. Thus, we cannot yet determine the directionality of the observed changes in the gut microbiota in $\mathrm{AD}$, e.g., whether gut microbiome dysbiosis is due to altered diet, medication use, or stress in individuals with AD. However, preclinical murine models of $\mathrm{AD}$ pathologies demonstrate altered gut microbiota prior to emergence of amyloidosis, tauopathy, or neuroinflammation, which provides some, but limited, evidence that changes in the gut microbiome may contribute to AD progression. Future longitudinal, cross-sectional, and interventional studies in $\mathrm{AD}$ patients are warranted to study key changes in the gut microbiota composition, mechanistic pathways, and possible therapeutics.

In a broader sense, treatment of disease through modification of the gut microbiome is extremely challenging due to the myriad of factors that shape microbiome composition and function. Development of the gut microbiome begins at birth, and rapidly changes during the first three years of life [186]. The gut microbiome is influenced by host genetics, mode of delivery, diets, surrounding environment, and lifestyles of individuals, and even psychological factors such as stress and anxiety [187-190]. For this reason, it is difficult to accurately distinguish which gut microbiota contributes to the onset or progression of Alzheimer's disease, and even if such gut microbiota is found, it is difficult to modify and maintain changes to the gut microbiome. Patients with Alzheimer's disease experience a range of dietary, medical, and stress-related changes as dementia progresses, which may influence the composition of the gut microbiome independent of disease pathologies. For future studies, it is important to have accurate understandings of how modifying the gut microbiome can contribute to health status of AD patients, and to determine how to maintain a healthy microbiome using a combination of rationally-developed probiotics (live microorganisms that confer a health benefit), prebiotics (non-digestible dietary ingredients that promote the growth of beneficial microorganisms), or dietary interventions.

\section{Conclusions}

Thus far, we have summarized the role of the gut microbiota-brain axis as an integral part of disease pathogenesis. However, this complex system employs a myriad of mechanisms working together in the development of $\mathrm{AD}$. While there are many moving factors in $\mathrm{AD}$ pathophysiology, identifying key pathways and mechanisms involved in progression is crucial in order to develop novel therapeutic targets. Growing evidence supports bidirectional communication between the CNS and the gut microbiota; studies demonstrate that the microbiota shapes AD pathologies and neuroinflammation, and $\mathrm{AD}$ pathogenesis modulates the gut microbiota composition. The gut microbiota-brain axis modulates key processes, including immune cell maturation, SCFA, LPS, and cytokine production, permeability of the gut epithelium and BBB, and gut microbiota diversity. Gut microbiota production of SCFA is reduced in AD thereby inducing the NF-KB pathway and increasing production of proinflammatory cytokines, including IL-1 $\beta$, IL-6, and TNF- $\alpha$ [191]. These 
cytokines are able to modulate the BBB permeability and translocate to the brain [113]. Once in the brain, proinflammatory cytokines potentiate $\mathrm{A} \beta$ deposition, tau hyperphosphorylation, microgliosis, and astrogliosis, increasing the severity of AD pathologies. Further studies are warranted to identify the directionality of observed changes in the microbiota, mechanisms, and therapeutic strategies with these novel targets. In particular, focus on elucidating the interactions between the gut microbiota communities and cytokines and their role in neuroinflammation and disease pathologies will lead to a better understanding of disease mechanisms. Studies with a multi-omics approach in both animal models, carefully selected human cohorts, and in vitro mechanistic studies will uncover the underlying mechanisms of the gut microbiota-brain axis and its impact on AD, dementia, and other neurological diseases. Focus on neuroinflammation and cytokines in the gut microbiota-brain axis will elucidate the role of chronic inflammation in $\mathrm{AD}$ and other inflammatory diseases.

Author Contributions: E.M.B. wrote and revised the manuscript. K.L. and E.K.C. edited and revised the manuscript. All authors have read and agreed to the published version of the manuscript.

Funding: E.K.C. is supported by a research grant funded by the Arizona Alzheimer's Consortium.

Acknowledgments: We would like to acknowledge the Pathogen and Microbiome Institute and members of our lab not listed as authors above for continued support.

Conflicts of Interest: The authors declare that they have no conflict of interest.

\section{References}

1. Thursby, E.; Juge, N. Introduction to the human gut microbiota. Biochem. J. 2017, 474, 1823-1836. [CrossRef] [PubMed]

2. Jandhyala, S.M. Role of the normal gut microbiota. World J. Gastroenterol. 2015, 21, 8787. [CrossRef] [PubMed]

3. Barcel'o-Coblijn, G.; Amedei, A. The Interplay of Microbiome and Immune Response in Health and Diseases; MDPI: Basel, Switzerland, 2019; ISBN 9783039216468.

4. Dinan, T.G.; Cryan, J.F. The Microbiome-Gut-Brain Axis in Health and Disease. Gastroenterol. Clin. N. Am. 2017, 46, 77-89. [CrossRef] [PubMed]

5. Ubeda, C.; Djukovic, A.; Isaac, S. Roles of the intestinal microbiota in pathogen protection. Clin. Transl. Immunol. 2017, 6, e128. [CrossRef] [PubMed]

6. Oliphant, K.; Allen-Vercoe, E. Macronutrient metabolism by the human gut microbiome: Major fermentation by-products and their impact on host health. Microbiome 2019, 7, 91. [CrossRef] [PubMed]

7. Kho, Z.Y.; Lal, S.K. The Human Gut Microbiome-A Potential Controller of Wellness and Disease. Front. Microbiol. 2018, 9, 1835. [CrossRef]

8. Tap, J.; Mondot, S.; Levenez, F.; Pelletier, E.; Caron, C.; Furet, J.-P.; Ugarte, E.; Muñoz-Tamayo, R.; Paslier, D.L.E.; Nalin, R.; et al. Towards the human intestinal microbiota phylogenetic core. Environ. Microbiol. 2009, 11, 2574-2584. [CrossRef]

9. Soto-Martin, E.C.; Warnke, I.; Farquharson, F.M.; Christodoulou, M.; Horgan, G.; Derrien, M.; Faurie, J.-M.; Flint, H.J.; Duncan, S.H.; Louis, P. Vitamin Biosynthesis by Human Gut Butyrate-Producing Bacteria and Cross-Feeding in Synthetic Microbial Communities. MBio 2020, 11. [CrossRef]

10. Yoshii, K.; Hosomi, K.; Sawane, K.; Kunisawa, J. Metabolism of Dietary and Microbial Vitamin B Family in the Regulation of Host Immunity. Front. Nutr. 2019, 6, 48. [CrossRef] [PubMed]

11. Atarashi, K.; Tanoue, T.; Shima, T.; Imaoka, A.; Kuwahara, T.; Momose, Y.; Cheng, G.; Yamasaki, S.; Saito, T.; Ohba, Y.; et al. Induction of Colonic Regulatory T Cells by Indigenous Clostridium Species. Science 2011, 331, 337-341. [CrossRef]

12. Makki, K.; Deehan, E.C.; Walter, J.; Bäckhed, F. The Impact of Dietary Fiber on Gut Microbiota in Host Health and Disease. Cell Host Microbe 2018, 23, 705-715. [CrossRef]

13. Trompette, A.; Gollwitzer, E.S.; Yadava, K.; Sichelstiel, A.K.; Sprenger, N.; Ngom-Bru, C.; Blanchard, C.; Junt, T.; Nicod, L.P.; Harris, N.L.; et al. Gut microbiota metabolism of dietary fiber influences allergic airway disease and hematopoiesis. Nat. Med. 2014, 20, 159-166. [CrossRef]

14. Trompette, A.; Gollwitzer, E.S.; Pattaroni, C.; Lopez-Mejia, I.C.; Riva, E.; Pernot, J.; Ubags, N.; Fajas, L.; Nicod, L.P.; Marsland, B.J. Dietary Fiber Confers Protection against Flu by Shaping Ly6c- Patrolling Monocyte Hematopoiesis and CD8 T Cell Metabolism. Immunity 2018, 48, 992-1005.e8. [CrossRef] 
15. Yu, L.C.-H. Microbiota dysbiosis and barrier dysfunction in inflammatory bowel disease and colorectal cancers: Exploring a common ground hypothesis. J. Biomed. Sci. 2018, 25, 79. [CrossRef]

16. Henke, M.T.; Kenny, D.J.; Cassilly, C.D.; Vlamakis, H.; Xavier, R.J.; Clardy, J. Ruminococcus gnavus, a member of the human gut microbiome associated with Crohn's disease, produces an inflammatory polysaccharide. Proc. Natl. Acad. Sci. USA 2019, 116, 12672-12677. [CrossRef] [PubMed]

17. Kowalski, K.; Mulak, A. Brain-Gut-Microbiota Axis in Alzheimer's Disease. J. Neurogastroenterol. Motil. 2019, 25, 48-60. [CrossRef]

18. Baker, J.M.; Al-Nakkash, L.; Herbst-Kralovetz, M.M. Estrogen-gut microbiome axis: Physiological and clinical implications. Maturitas 2017, 103, 45-53. [CrossRef]

19. Flores, R.; Shi, J.; Fuhrman, B.; Xu, X.; Veenstra, T.D.; Gail, M.H.; Gajer, P.; Ravel, J.; Goedert, J.J. Fecal microbial determinants of fecal and systemic estrogens and estrogen metabolites: A cross-sectional study. J. Transl. Med. 2012, 10, 253. [CrossRef]

20. Fülling, C.; Dinan, T.G.; Cryan, J.F. Gut Microbe to Brain Signaling: What Happens in Vagus ... . Neuron 2019, 101, 998-1002.

21. Bravo, J.A.; Forsythe, P.; Chew, M.V.; Escaravage, E.; Savignac, H.M.; Dinan, T.G.; Bienenstock, J.; Cryan, J.F. Ingestion of Lactobacillus strain regulates emotional behavior and central GABA receptor expression in a mouse via the vagus nerve. Proc. Natl. Acad. Sci. USA 2011, 108, 16050-16055. [CrossRef] [PubMed]

22. Brandsma, E.; Kloosterhuis, N.J.; Koster, M.; Dekker, D.C.; Gijbels, M.J.J.; van der Velden, S.; Ríos-Morales, M.; van Faassen, M.J.R.; Loreti, M.G.; de Bruin, A.; et al. A Proinflammatory Gut Microbiota Increases Systemic Inflammation and Accelerates Atherosclerosis. Circ. Res. 2019, 124, 94-100. [CrossRef]

23. Ma, Q.; Xing, C.; Long, W.; Wang, H.Y.; Liu, Q.; Wang, R.-F. Impact of microbiota on central nervous system and neurological diseases: The gut-brain axis. J. Neuroinflamm. 2019, 16, 53. [CrossRef]

24. Alkasir, R.; Li, J.; Li, X.; Jin, M.; Zhu, B. Human gut microbiota: The links with dementia development. Protein Cell 2017, 8, 90-102. [CrossRef]

25. Saji, N.; Murotani, K.; Hisada, T.; Kunihiro, T.; Tsuduki, T.; Sugimoto, T.; Kimura, A.; Niida, S.; Toba, K.; Sakurai, T. Relationship between dementia and gut microbiome-associated metabolites: A cross-sectional study in Japan. Sci. Rep. 2020, 10, 8088. [CrossRef]

26. Li, S.; Shao, Y.; Li, K.; HuangFu, C.; Wang, W.; Liu, Z.; Cai, Z.; Zhao, B. Vascular Cognitive Impairment and the Gut Microbiota. J. Alzheimers Dis. 2018, 63, 1209-1222. [CrossRef] [PubMed]

27. Daulatzai, M.A. Non-celiac gluten sensitivity triggers gut dysbiosis, neuroinflammation, gut-brain axis dysfunction, and vulnerability for dementia. CNS Neurol. Disord. Drug Targets 2015, 14, 110-131. [CrossRef] [PubMed]

28. Mohan, M.; Okeoma, C.M.; Sestak, K. Dietary Gluten and Neurodegeneration: A Case for Preclinical Studies. Int. J. Mol. Sci. 2020, 21, 5407. [CrossRef]

29. Pennisi, M.; Bramanti, A.; Cantone, M.; Pennisi, G.; Bella, R.; Lanza, G. Neurophysiology of the "Celiac Brain": Disentangling Gut-Brain Connections. Front. Neurosci. 2017, 11, 498. [CrossRef]

30. Lanza, G.; Bella, R.; Cantone, M.; Pennisi, G.; Ferri, R.; Pennisi, M. Cognitive Impairment and Celiac Disease: Is Transcranial Magnetic Stimulation a Trait d'Union between Gut and Brain? Int. J. Mol. Sci. 2018, 19, 2243. [CrossRef]

31. Lyon, L. "All disease begins in the gut": Was Hippocrates right? Brain 2018, 141, e20. [CrossRef]

32. Hippius, H.; Neundörfer, G. The discovery of Alzheimer's disease. Dialogues Clin. Neurosci. 2003, 5, 101-108.

33. Alzheimer's Association. 2020 Alzheimer's disease facts and figures. Alzheimers Dement. 2020, 5, $234-270$. [CrossRef]

34. Lewis, T.J.; Trempe, C.L. The Amyloid Cascade Hypothesis. The End of Alzheimer's: The Brain and Beyond; Academic Press: Cambridge, MA, USA, 2017; pp. 26-50.

35. Wang, X.; Sun, G.; Feng, T.; Zhang, J.; Huang, X.; Wang, T.; Xie, Z.; Chu, X.; Yang, J.; Wang, H.; et al. Sodium oligomannate therapeutically remodels gut microbiota and suppresses gut bacterial amino acids-shaped neuroinflammation to inhibit Alzheimer's disease progression. Cell Res. 2019, 29, 787-803. [CrossRef] [PubMed]

36. Bitan, G.; Kirkitadze, M.D.; Lomakin, A.; Vollers, S.S.; Benedek, G.B.; Teplow, D.B. Amyloid beta -protein (Abeta) assembly: Abeta 40 and Abeta 42 oligomerize through distinct pathways. Proc. Natl. Acad. Sci. USA 2003, 100, 330-335. [CrossRef]

37. Selkoe, D.J. Alzheimer's disease: Genes, proteins, and therapy. Physiol. Rev. 2001, 81, 741-766. [CrossRef] 
38. Sochocka, M.; Donskow-Łysoniewska, K.; Diniz, B.S.; Kurpas, D.; Brzozowska, E.; Leszek, J. The Gut Microbiome Alterations and Inflammation-Driven Pathogenesis of Alzheimer's Disease-A Critical Review. Mol. Neurobiol. 2019, 56, 1841-1851. [CrossRef]

39. Hashemiaghdam, A.; Mroczek, M. Microglia heterogeneity and neurodegeneration: The emerging paradigm of the role of immunity in Alzheimer's disease. J. Neuroimmunol. 2020, 341, 577185. [CrossRef]

40. Kinney, J.W.; Bemiller, S.M.; Murtishaw, A.S.; Leisgang, A.M.; Salazar, A.M.; Lamb, B.T. Inflammation as a central mechanism in Alzheimer's disease. Alzheimers. Dement. 2018, 4, 575-590. [CrossRef]

41. Jill, E.; Clarridge, I.I.I. Impact of 16S rRNA Gene Sequence Analysis for Identification of Bacteria on Clinical Microbiology and Infectious Diseases. Clin. Microbiol. Rev. 2004, 17, 840-862.

42. Ihrmark, K.; Bödeker, I.T.M.; Cruz-Martinez, K.; Friberg, H.; Kubartova, A.; Schenck, J.; Strid, Y.; Stenlid, J.; Brandström-Durling, M.; Clemmensen, K.E.; et al. New primers to amplify the fungal ITS2 region-evaluation by 454-sequencing of artificial and natural communities. FEMS Microbiol. Ecol. 2012, 82, 666-677. [CrossRef] [PubMed]

43. Hillmann, B.; Al-Ghalith, G.A.; Shields-Cutler, R.R.; Zhu, Q.; Gohl, D.M.; Beckman, K.B.; Knight, R.; Knights, D. Evaluating the Information Content of Shallow Shotgun Metagenomics. MSystems 2018, 3. [CrossRef]

44. Aguiar-Pulido, V.; Huang, W.; Suarez-Ulloa, V.; Cickovski, T.; Mathee, K.; Narasimhan, G. Metagenomics, Metatranscriptomics, and Metabolomics Approaches for Microbiome Analysis. Evol. Bioinform. Online 2016, 12. [CrossRef] [PubMed]

45. Liu, P.-P.; Xie, Y.; Meng, X.-Y.; Kang, J.-S. Author Correction: History and progress of hypotheses and clinical trials for Alzheimer's disease. Signal Transduct. Target. Ther. 2019, 4, 29. [CrossRef]

46. Sun, M.; Ma, K.; Wen, J.; Wang, G.; Zhang, C.; Li, Q.; Bao, X.; Wang, H. A Review of the Brain-Gut-Microbiome Axis and the Potential Role of Microbiota in Alzheimer's Disease. J. Alzheimer's Dis. 2020, 73, 849-865. [CrossRef]

47. Giau, V.; Wu, S.; Jamerlan, A.; An, S.; Kim, S.; Hulme, J. Gut Microbiota and Their Neuroinflammatory Implications in Alzheimer's Disease. Nutrients 2018, 10, 1765. [CrossRef] [PubMed]

48. Domingues, C.; da Cruz e Silva, O.A.B.; Henriques, A.G. Impact of Cytokines and Chemokines on Alzheimer's Disease Neuropathological Hallmarks. Curr. Alzheimer Res. 2017, 14, 870-882. [CrossRef]

49. Sheng, J.G.; Ito, K.; Skinner, R.D.; Mrak, R.E.; Rovnaghi, C.R.; Van Eldik, L.J.; Griffin, W.S. In vivo and in vitro evidence supporting a role for the inflammatory cytokine interleukin-1 as a driving force in Alzheimer pathogenesis. Neurobiol. Aging 1996, 17, 761-766. [CrossRef]

50. Quintanilla, R.A.; Orellana, D.I.; González-Billault, C.; Maccioni, R.B. Interleukin-6 induces Alzheimer-type phosphorylation of tau protein by deregulating the cdk5/p35 pathway. Exp. Cell Res. 2004, 295, 245-257. [CrossRef]

51. Steardo, L.; Bronzuoli, M.R.; Iacomino, A.; Esposito, G.; Steardo, L.; Scuderi, C. Does neuroinflammation turn on the flame in Alzheimer's disease? Focus on astrocytes. Front. Neurosci. 2015, 9, 259. [CrossRef]

52. Koeth, R.A.; Wang, Z.; Levison, B.S.; Buffa, J.A.; Org, E.; Sheehy, B.T.; Britt, E.B.; Fu, X.; Wu, Y.; Li, L.; et al. Intestinal microbiota metabolism of L-carnitine, a nutrient in red meat, promotes atherosclerosis. Nat. Med. 2013, 19, 576-585. [CrossRef]

53. Vogt, N.M.; Romano, K.A.; Darst, B.F.; Engelman, C.D.; Johnson, S.C.; Carlsson, C.M.; Asthana, S.; Blennow, K.; Zetterberg, H.; Bendlin, B.B.; et al. The gut microbiota-derived metabolite trimethylamine N-oxide is elevated in Alzheimer's disease. Alzheimer's Res. Ther. 2018, 10, 124. [CrossRef]

54. Ho, L.; Ono, K.; Tsuji, M.; Mazzola, P.; Singh, R.; Pasinetti, G.M. Protective roles of intestinal microbiota derived short chain fatty acids in Alzheimer's disease-type beta-amyloid neuropathological mechanisms. Expert Rev. Neurother. 2018, 18, 83-90. [CrossRef]

55. Rao, M.; Gershon, M.D. The bowel and beyond: The enteric nervous system in neurological disorders. Nat. Rev. Gastroenterol. Hepatol. 2016, 13, 517-528. [CrossRef] [PubMed]

56. Costa, M.; Brookes, S.J.; Hennig, G.W. Anatomy and physiology of the enteric nervous system. Gut 2000, 47 (Suppl. 4), iv15-iv19. [CrossRef]

57. Abdel-Haq, R.; Schlachetzki, J.C.M.; Glass, C.K.; Mazmanian, S.K. Microbiome-microglia connections via the gut-brain axis. J. Exp. Med. 2019, 216, 41-59. [CrossRef] [PubMed]

58. Bonaz, B.; Sinniger, V.; Pellissier, S. The Vagus Nerve in the Neuro-Immune Axis: Implications in the Pathology of the Gastrointestinal Tract. Front. Immunol. 2017, 8, 1452. [CrossRef] [PubMed] 
59. Bonaz, B.; Bazin, T.; Pellissier, S. The Vagus Nerve at the Interface of the Microbiota-Gut-Brain Axis. Front. Neurosci. 2018, 12, 49. [CrossRef]

60. Browning, K.N. Role of central vagal 5-HT3 receptors in gastrointestinal physiology and pathophysiology. Front. Neurosci. 2015, 9, 413. [CrossRef]

61. Merrill, C.A.; Jonsson, M.A.G.; Minthon, L.; Ejnell, H.; C-son Silander, H.; Blennow, K.; Karlsson, M.; Nordlund, A.; Rolstad, S.; Warkentin, S.; et al. Vagus nerve stimulation in patients with Alzheimer's disease: Additional follow-up results of a pilot study through 1 year. J. Clin. Psychiatry 2006, 67, 1171-1178. [CrossRef]

62. Sjögren, M.J.C.; Hellström, P.T.O.; Jonsson, M.A.G.; Runnerstam, M.; Silander, H.C.-S.; Ben-Menachem, E. Cognition-enhancing effect of vagus nerve stimulation in patients with Alzheimer's disease: A pilot study. J. Clin. Psychiatry 2002, 63, 972-980. [CrossRef]

63. Desbeaumes Jodoin, V.; Richer, F.; Miron, J.-P.; Fournier-Gosselin, M.-P.; Lespérance, P. Long-term Sustained Cognitive Benefits of Vagus Nerve Stimulation in Refractory Depression. J. ECT 2018, 34, 283-290. [CrossRef]

64. Kaczmarczyk, R.; Tejera, D.; Simon, B.J.; Heneka, M.T. Microglia modulation through external vagus nerve stimulation in a murine model of Alzheimer's disease. J. Neurochem. 2018, 146, 76-85. [CrossRef]

65. Tran, T.T.T.; Corsini, S.; Kellingray, L.; Hegarty, C.; Le Gall, G.; Narbad, A.; Müller, M.; Tejera, N.; O’Toole, P.W.; Minihane, A.-M.; et al. APOE genotype influences the gut microbiome structure and function in humans and mice: Relevance for Alzheimer's disease pathophysiology. FASEB J. 2019, 33, 8221-8231. [CrossRef]

66. Vogt, N.M.; Kerby, R.L.; Dill-McFarland, K.A.; Harding, S.J.; Merluzzi, A.P.; Johnson, S.C.; Carlsson, C.M.; Asthana, S.; Zetterberg, H.; Blennow, K.; et al. Gut microbiome alterations in Alzheimer's disease. Sci. Rep. 2017, 7, 13537. [CrossRef]

67. Liu, P.; Wu, L.; Peng, G.; Han, Y.; Tang, R.; Ge, J.; Zhang, L.; Jia, L.; Yue, S.; Zhou, K.; et al. Altered microbiomes distinguish Alzheimer's disease from amnestic mild cognitive impairment and health in a Chinese cohort. Brain Behav. Immun. 2019, 80, 633-643. [CrossRef]

68. Zhuang, Z.-Q.; Shen, L.-L.; Li, W.-W.; Fu, X.; Zeng, F.; Gui, L.; Lü, Y.; Cai, M.; Zhu, C.; Tan, Y.-L.; et al. Gut Microbiota is Altered in Patients with Alzheimer's Disease. J. Alzheimers Dis. 2018, 63, 1337-1346. [CrossRef] [PubMed]

69. Haran, J.P.; Bhattarai, S.K.; Foley, S.E.; Dutta, P.; Ward, D.V.; Bucci, V.; McCormick, B.A. Alzheimer's Disease Microbiome Is Associated with Dysregulation of the Anti-Inflammatory P-Glycoprotein Pathway. MBio 2019, 10. [CrossRef]

70. Emery, D.C.; Shoemark, D.K.; Batstone, T.E.; Waterfall, C.M.; Coghill, J.A.; Cerajewska, T.L.; Davies, M.; West, N.X.; Allen, S.J. 16S rRNA Next Generation Sequencing Analysis Shows Bacteria in Alzheimer's Post-Mortem Brain. Front. Aging Neurosci. 2017, 9, 195. [CrossRef] [PubMed]

71. Dominy, S.S.; Lynch, C.; Ermini, F.; Benedyk, M.; Marczyk, A.; Konradi, A.; Nguyen, M.; Haditsch, U.; Raha, D.; Griffin, C.; et al. Porphyromonas gingivalis in Alzheimer's disease brains: Evidence for disease causation and treatment with small-molecule inhibitors. Sci. Adv. 2019, 5, eaau3333. [CrossRef]

72. Chen, Y.; Fang, L.; Chen, S.; Zhou, H.; Fan, Y.; Lin, L.; Li, J.; Xu, J.; Chen, Y.; Ma, Y.; et al. Gut Microbiome Alterations Precede Cerebral Amyloidosis and Microglial Pathology in a Mouse Model of Alzheimer's Disease. BioMed. Res. Int. 2020, 2020, 1-15. [CrossRef] [PubMed]

73. Brandscheid, C.; Schuck, F.; Reinhardt, S.; Schäfer, K.-H.; Pietrzik, C.U.; Grimm, M.; Hartmann, T.; Schwiertz, A.; Endres, K. Altered Gut Microbiome Composition and Tryptic Activity of the 5xFAD Alzheimer's Mouse Model. J. Alzheimer's Dis. 2017, 56, 775-788. [CrossRef]

74. Parikh, I.J.; Estus, J.L.; Zajac, D.J.; Malik, M.; Maldonado Weng, J.; Tai, L.M.; Chlipala, G.E.; LaDu, M.J.; Green, S.J.; Estus, S. Murine Gut Microbiome Association with APOE Alleles. Front. Immunol. 2020, 11, 200. [CrossRef]

75. Harach, T.; Marungruang, N.; Duthilleul, N.; Cheatham, V.; Mc Coy, K.D.; Frisoni, G.; Neher, J.J.; Fåk, F.; Jucker, M.; Lasser, T.; et al. Erratum: Reduction of Abeta amyloid pathology in APPPS1 transgenic mice in the absence of gut microbiota. Sci. Rep. 2017, 7, 41802. [CrossRef]

76. Bonfili, L.; Cecarini, V.; Berardi, S.; Scarpona, S.; Suchodolski, J.S.; Nasuti, C.; Fiorini, D.; Boarelli, M.C.; Rossi, G.; Eleuteri, A.M. Microbiota modulation counteracts Alzheimer's disease progression influencing neuronal proteolysis and gut hormones plasma levels. Sci. Rep. 2017, 7, 2426. [CrossRef]

77. Sun, J.; Liu, S.; Ling, Z.; Wang, F.; Ling, Y.; Gong, T.; Fang, N.; Ye, S.; Si, J.; Liu, J. Fructooligosaccharides Ameliorating Cognitive Deficits and Neurodegeneration in APP/PS1 Transgenic Mice through Modulating Gut Microbiota. J. Agric. Food Chem. 2019, 67, 3006-3017. [CrossRef] 
78. Sanguinetti, E.; Collado, M.C.; Marrachelli, V.G.; Monleon, D.; Selma-Royo, M.; Pardo-Tendero, M.M.; Burchielli, S.; Iozzo, P. Microbiome-metabolome signatures in mice genetically prone to develop dementia, fed a normal or fatty diet. Sci. Rep. 2018, 8, 4907. [CrossRef] [PubMed]

79. Sun, J.; Xu, J.; Ling, Y.; Wang, F.; Gong, T.; Yang, C.; Ye, S.; Ye, K.; Wei, D.; Song, Z.; et al. Fecal microbiota transplantation alleviated Alzheimer's disease-like pathogenesis in APP/PS1 transgenic mice. Transl. Psychiatry 2019, 9, 189. [CrossRef]

80. Chen, W.-W.; Zhang, X.; Huang, W.-J. Role of neuroinflammation in neurodegenerative diseases (Review). Mol. Med. Rep. 2016, 13, 3391-3396. [CrossRef]

81. Guo, W.; Wang, H.; Watanabe, M.; Shimizu, K.; Zou, S.; LaGraize, S.C.; Wei, F.; Dubner, R.; Ren, K. Glial-cytokine-neuronal interactions underlying the mechanisms of persistent pain. J. Neurosci. 2007, 27, 6006-6018. [CrossRef]

82. Ferrucci, L.; Fabbri, E. Inflammageing: Chronic inflammation in ageing, cardiovascular disease, and frailty. Nat. Rev. Cardiol. 2018, 15, 505-522. [CrossRef] [PubMed]

83. Pan, J.; Ma, N.; Yu, B.; Zhang, W.; Wan, J. Transcriptomic profiling of microglia and astrocytes throughout aging. J. Neuroinflamm. 2020, 17, 97. [CrossRef]

84. Salas, I.H.; Burgado, J.; Allen, N.J. Glia: Victims or villains of the aging brain? Neurobiol. Dis. 2020, 143, 105008. [CrossRef] [PubMed]

85. Streit, W.J.; Sammons, N.W.; Kuhns, A.J.; Larry Sparks, D. Dystrophic microglia in the aging human brain. Glia 2004, 45, 208-212. [CrossRef] [PubMed]

86. Fransen, F.; van Beek, A.A.; Borghuis, T.; Aidy, S.E.; Hugenholtz, F.; van der Gaast-de Jongh, C.; Savelkoul, H.F.J.; De Jonge, M.I.; Boekschoten, M.V.; Smidt, H.; et al. Aged Gut Microbiota Contributes to Systemical Inflammaging after Transfer to Germ-Free Mice. Front. Immunol. 2017, 8, 1385. [CrossRef]

87. Cerovic, M.; Forloni, G.; Balducci, C. Neuroinflammation and the Gut Microbiota: Possible Alternative Therapeutic Targets to Counteract Alzheimer's Disease? Front. Aging Neurosci. 2019, 11, 284. [CrossRef]

88. Arcuri, C.; Mecca, C.; Bianchi, R.; Giambanco, I.; Donato, R. The Pathophysiological Role of Microglia in Dynamic Surveillance, Phagocytosis and Structural Remodeling of the Developing CNS. Front. Mol. Neurosci. 2017, 10, 191. [CrossRef] [PubMed]

89. Leyns, C.E.G.; Holtzman, D.M. Glial contributions to neurodegeneration in tauopathies. Mol. Neurodegener. 2017, 12, 50. [CrossRef]

90. Wang, Y.; Wang, Z.; Wang, Y.; Li, F.; Jia, J.; Song, X.; Qin, S.; Wang, R.; Jin, F.; Kitazato, K.; et al. The Gut-Microglia Connection: Implications for Central Nervous System Diseases. Front. Immunol. 2018, 9, 2325. [CrossRef]

91. Hemonnot, A.-L.; Hua, J.; Ulmann, L.; Hirbec, H. Microglia in Alzheimer Disease: Well-Known Targets and New Opportunities. Front. Aging Neurosci. 2019, 11, 233. [CrossRef]

92. Lai, A.Y.; McLaurin, J. Clearance of amyloid- $\beta$ peptides by microglia and macrophages: The issue of what, when and where. Future Neurol. 2012, 7, 165-176. [CrossRef]

93. Mandrekar-Colucci, S.; Landreth, G.E. Microglia and Inflammation in Alzheimers Disease. CNS Neurol. Disord.-Drug Targets 2010, 9, 156-167. [CrossRef]

94. Hristovska, I.; Pascual, O. Deciphering Resting Microglial Morphology and Process Motility from a Synaptic Prospect. Front. Integr. Neurosci. 2015, 9, 73. [CrossRef]

95. Streit, W.J.; Mrak, R.E.; Griffin, W.S.T. Microglia and neuroinflammation: A pathological perspective. J. Neuroinflammation 2004, 1, 14. [CrossRef] [PubMed]

96. Meneses, G.; Bautista, M.; Florentino, A.; Díaz, G.; Acero, G.; Besedovsky, H.; Meneses, D.; Fleury, A.; Del Rey, A.; Gevorkian, G.; et al. Electric stimulation of the vagus nerve reduced mouse neuroinflammation induced by lipopolysaccharide. J. Inflamm. 2016, 13, 33. [CrossRef]

97. Huffman, W.J.; Subramaniyan, S.; Rodriguiz, R.M.; Wetsel, W.C.; Grill, W.M.; Terrando, N. Modulation of neuroinflammation and memory dysfunction using percutaneous vagus nerve stimulation in mice. Brain Stimul. 2019, 12, 19-29. [CrossRef] [PubMed]

98. Yao, K.; Zu, H.-B. Microglial polarization: Novel therapeutic mechanism against Alzheimer's disease. Inflammopharmacology 2020, 28, 95-110. [CrossRef]

99. Chhor, V.; Le Charpentier, T.; Lebon, S.; Oré, M.-V.; Celador, I.L.; Josserand, J.; Degos, V.; Jacotot, E.; Hagberg, H.; Sävman, K.; et al. Characterization of phenotype markers and neuronotoxic potential of polarised primary microglia in vitro. Brain Behav. Immun. 2013, 32, 70-85. [CrossRef] 
100. Zhang, L.; Wang, Y.; Xiayu, X.; Shi, C.; Chen, W.; Song, N.; Fu, X.; Zhou, R.; Xu, Y.-F.; Huang, L.; et al. Altered Gut Microbiota in a Mouse Model of Alzheimer's Disease. J. Alzheimer's Dis. 2017, 60, 1241-1257. [CrossRef]

101. Amici, S.A.; Dong, J.; Guerau-de-Arellano, M. Molecular Mechanisms Modulating the Phenotype of Macrophages and Microglia. Front. Immunol. 2017, 8, 1520. [CrossRef]

102. Tang, Y.; Le, W. Differential Roles of M1 and M2 Microglia in Neurodegenerative Diseases. Mol. Neurobiol. 2016, 53, 1181-1194. [CrossRef] [PubMed]

103. Bachiller, S.; Jiménez-Ferrer, I.; Paulus, A.; Yang, Y.; Swanberg, M.; Deierborg, T.; Boza-Serrano, A. Microglia in Neurological Diseases: A Road Map to Brain-Disease Dependent-Inflammatory Response. Front. Cell. Neurosci. 2018, 12, 488. [CrossRef]

104. Sharma, R.K.; Yang, T.; Oliveira, A.C.; Lobaton, G.O.; Aquino, V.; Kim, S.; Richards, E.M.; Pepine, C.J.; Sumners, C.; Raizada, M.K. Microglial Cells Impact Gut Microbiota and Gut Pathology in Angiotensin II-Induced Hypertension. Circ. Res. 2019, 124, 727-736. [CrossRef]

105. Siracusa, R.; Fusco, R.; Cuzzocrea, S. Astrocytes: Role and Functions in Brain Pathologies. Front. Pharmacol. 2019, 10, 1114. [CrossRef]

106. Sofroniew, M.V.; Vinters, H.V. Astrocytes: Biology and pathology. Acta Neuropathol. 2010, 119, 7-35. [CrossRef]

107. González-Reyes, R.E.; Nava-Mesa, M.O.; Vargas-Sánchez, K.; Ariza-Salamanca, D.; Mora-Muñoz, L. Involvement of Astrocytes in Alzheimer's Disease from a Neuroinflammatory and Oxidative Stress Perspective. Front. Mol. Neurosci. 2017, 10, 427. [CrossRef]

108. Michinaga, S.; Koyama, Y. Dual Roles of Astrocyte-Derived Factors in Regulation of Blood-Brain Barrier Function after Brain Damage. Int. J. Mol. Sci. 2019, 20, 571. [CrossRef] [PubMed]

109. Csipo, T.; Lipecz, A.; Ashpole, N.M.; Balasubramanian, P.; Tarantini, S. Astrocyte senescence contributes to cognitive decline. GeroScience 2020, 42, 51-55. [CrossRef]

110. Zenaro, E.; Piacentino, G.; Constantin, G. The blood-brain barrier in Alzheimer's disease. Neurobiol. Dis. 2017, 107, 41-56. [CrossRef]

111. Van de Haar, H.J.; Burgmans, S.; Jansen, J.F.A.; van Osch, M.J.P.; van Buchem, M.A.; Muller, M.; Hofman, P.A.M.; Verhey, F.R.J.; Backes, W.H. Blood-Brain Barrier Leakage in Patients with Early Alzheimer Disease. Radiology 2017, 282, 615. [CrossRef] [PubMed]

112. Yarlagadda, A.; Alfson, E.; Clayton, A.H. The blood brain barrier and the role of cytokines in neuropsychiatry. Psychiatry 2009, 6, 18-22. [PubMed]

113. Pan, W.; Stone, K.P.; Hsuchou, H.; Manda, V.K.; Zhang, Y.; Kastin, A.J. Cytokine Signaling Modulates Blood-Brain Barrier Function. Curr. Pharm. Des. 2011, 17, 3729-3740. [CrossRef]

114. Hyvärinen, T.; Hagman, S.; Ristola, M.; Sukki, L.; Veijula, K.; Kreutzer, J.; Kallio, P.; Narkilahti, S. Co-stimulation with IL-1 $\beta$ and TNF- $\alpha$ induces an inflammatory reactive astrocyte phenotype with neurosupportive characteristics in a human pluripotent stem cell model system. Sci. Rep. 2019, 9, 16944. [CrossRef]

115. Wang, W.-Y.; Tan, M.-S.; Yu, J.-T.; Tan, L. Role of pro-inflammatory cytokines released from microglia in Alzheimer's disease. Ann. Transl. Med. 2015, 3, 136. [CrossRef]

116. Fakhoury, M. Microglia and Astrocytes in Alzheimer's Disease: Implications for Therapy. Curr. Neuropharmacol. 2018, 16, 508-518. [CrossRef]

117. Consonni, A.; Morara, S.; Codazzi, F.; Grohovaz, F.; Zacchetti, D. Inhibition of lipopolysaccharide-induced microglia activation by calcitonin gene related peptide and adrenomedullin. Mol. Cell. Neurosci. 2011, 48, 151-160. [CrossRef]

118. You, L.-H.; Yan, C.-Z.; Zheng, B.-J.; Ci, Y.-Z.; Chang, S.-Y.; Yu, P.; Gao, G.-F.; Li, H.-Y.; Dong, T.-Y.; Chang, Y.-Z. Astrocyte hepcidin is a key factor in LPS-induced neuronal apoptosis. Cell Death Dis. 2017, 8, e2676. [CrossRef]

119. Ryu, K.-Y.; Lee, H.-J.; Woo, H.; Kang, R.-J.; Han, K.-M.; Park, H.; Lee, S.M.; Lee, J.-Y.; Jeong, Y.J.; Nam, H.-W.; et al. Dasatinib regulates LPS-induced microglial and astrocytic neuroinflammatory responses by inhibiting AKT/STAT3 signaling. J. Neuroinflamm. 2019, 16, 190. [CrossRef] [PubMed]

120. Tomova, A.; Soltys, K.; Repiská, G.; Palkova, L.; Filcikova, D.; Minarik, G.; Turna, J.; Prochotska, K.; Babinska, K.; Ostatnikova, D. Specificity of gut microbiota in children with autism spectrum disorder in Slovakia and its correlation with astrocytes activity marker and specific behavioural patterns. Physiol. Behav. 2020, 214, 112745. [CrossRef] [PubMed] 
121. Liu, T.; Li, J.; Liu, Y.; Xiao, N.; Suo, H.; Xie, K.; Yang, C.; Wu, C. Short-Chain Fatty Acids Suppress Lipopolysaccharide-Induced Production of Nitric Oxide and Proinflammatory Cytokines Through Inhibition of NF-кB Pathway in RAW264.7 Cells. Inflammation 2012, 35, 1676-1684. [CrossRef]

122. Zhang, Y.; Huang, R.; Cheng, M.; Wang, L.; Chao, J.; Li, J.; Zheng, P.; Xie, P.; Zhang, Z.; Yao, H. Gut microbiota from NLRP3-deficient mice ameliorates depressive-like behaviors by regulating astrocyte dysfunction via circHIPK2. Microbiome 2019, 7, 116. [CrossRef]

123. Clark, R.I.; Salazar, A.; Yamada, R.; Fitz-Gibbon, S.; Morselli, M.; Alcaraz, J.; Rana, A.; Rera, M.; Pellegrini, M.; Ja, W.W.; et al. Distinct Shifts in Microbiota Composition during Drosophila Aging Impair Intestinal Function and Drive Mortality. Cell Rep. 2015, 12, 1656-1667. [CrossRef]

124. Conley, M.N.; Wong, C.P.; Duyck, K.M.; Hord, N.; Ho, E.; Sharpton, T.J. Aging and serum MCP-1 are associated with gut microbiome composition in a murine model. PeerJ 2016, 4, e1854. [CrossRef] [PubMed]

125. Thevaranjan, N.; Puchta, A.; Schulz, C.; Naidoo, A.; Szamosi, J.C.; Verschoor, C.P.; Loukov, D.; Schenck, L.P.; Jury, J.; Foley, K.P.; et al. Age-Associated Microbial Dysbiosis Promotes Intestinal Permeability, Systemic Inflammation, and Macrophage Dysfunction. Cell Host Microbe 2017, 21, 455-466.e4. [CrossRef] [PubMed]

126. Qin, L.; Wu, X.; Block, M.L.; Liu, Y.; Breese, G.R.; Hong, J.-S.; Knapp, D.J.; Crews, F.T. Systemic LPS causes chronic neuroinflammation and progressive neurodegeneration. Glia 2007, 55, 453-462. [CrossRef]

127. Friedland, R.P.; Chapman, M.R. The role of microbial amyloid in neurodegeneration. PLoS Pathog. 2017, 13, e1006654. [CrossRef]

128. Minter, M.R.; Zhang, C.; Leone, V.; Ringus, D.L.; Zhang, X.; Oyler-Castrillo, P.; Musch, M.W.; Liao, F.; Ward, J.F.; Holtzman, D.M.; et al. Antibiotic-induced perturbations in gut microbial diversity influences neuro-inflammation and amyloidosis in a murine model of Alzheimer's disease. Sci. Rep. 2016, 6, 30028. [CrossRef]

129. Wang, X.; Zhou, Y.; Ren, J.-J.; Hammer, N.D.; Chapman, M.R. Gatekeeper residues in the major curlin subunit modulate bacterial amyloid fiber biogenesis. Proc. Natl. Acad. Sci. USA. 2010, 107, 163-168. [CrossRef]

130. Chapman, M. P2-024: Protein misfolding done right: The biogenesis of bacterial amyloid fibers. Alzheimer's Dement. 2006, 2, S239. [CrossRef]

131. Andreasen, M.; Meisl, G.; Taylor, J.D.; Michaels, T.C.T.; Levin, A.; Otzen, D.E.; Chapman, M.R.; Dobson, C.M.; Matthews, S.J.; Knowles, T.P.J. Physical Determinants of Amyloid Assembly in Biofilm Formation. MBio 2019, 10. [CrossRef]

132. Biesecker, S.G.; Nicastro, L.K.; Wilson, R.P.; Tükel, Ç. The Functional Amyloid Curli Protects Escherichia coli against Complement-Mediated Bactericidal Activity. Biomolecules 2018, 8, 5. [CrossRef]

133. Lundmark, K.; Westermark, G.T.; Olsén, A.; Westermark, P. Protein fibrils in nature can enhance amyloid protein a amyloidosis in mice: Cross-seeding as a disease mechanism. Proc. Natl. Acad. Sci. USA 2005, 102, 6098-6102. [CrossRef]

134. Zhou, Y.; Smith, D.; Leong, B.J.; Brännström, K.; Almqvist, F.; Chapman, M.R. Promiscuous cross-seeding between bacterial amyloids promotes interspecies biofilms. J. Biol. Chem. 2012, 287, 35092-35103. [CrossRef]

135. Nishimori, J.H.; Newman, T.N.; Oppong, G.O.; Rapsinski, G.J.; Yen, J.-H.; Biesecker, S.G.; Wilson, R.P.; Butler, B.P.; Winter, M.G.; Tsolis, R.M.; et al. Microbial amyloids induce interleukin 17A (IL-17A) and IL-22 responses via Toll-like receptor 2 activation in the intestinal mucosa. Infect. Immun. 2012, 80, 4398-4408. [CrossRef]

136. Oppong, G.O.; Rapsinski, G.J.; Tursi, S.A.; Biesecker, S.G.; Klein-Szanto, A.J.; Goulian, M.; McCauley, C.; Healy, C.; Wilson, R.P.; Tükel, C. Biofilm-associated bacterial amyloids dampen inflammation in the gut: Oral treatment with curli fibres reduces the severity of hapten-induced colitis in mice. NPJ Biofilms Microbiomes 2015, 1, 15019. [CrossRef]

137. Brown, G.C. The endotoxin hypothesis of neurodegeneration. J. Neuroinflamm. 2019, 16, 180. [CrossRef]

138. Banks, W.A.; Gray, A.M.; Erickson, M.A.; Salameh, T.S.; Damodarasamy, M.; Sheibani, N.; Meabon, J.S.; Wing, E.E.; Morofuji, Y.; Cook, D.G.; et al. Lipopolysaccharide-induced blood-brain barrier disruption: Roles of cyclooxygenase, oxidative stress, neuroinflammation, and elements of the neurovascular unit. J. Neuroinflamm. 2015, 12, 223. [CrossRef]

139. Salguero, M.V.; Al-Obaide, M.A.I.; Singh, R.; Siepmann, T.; Vasylyeva, T.L. Dysbiosis of Gram-negative gut microbiota and the associated serum lipopolysaccharide exacerbates inflammation in type 2 diabetic patients with chronic kidney disease. Exp. Ther. Med. 2019, 18, 3461-3469. [CrossRef] 
140. Lukiw, W.J. Bacteroides fragilis Lipopolysaccharide and Inflammatory Signaling in Alzheimer's Disease. Front. Microbiol. 2016, 7, 1544. [CrossRef]

141. Daulatzai, M.A. Chronic functional bowel syndrome enhances gut-brain axis dysfunction, neuroinflammation, cognitive impairment, and vulnerability to dementia. Neurochem. Res. 2014, 39, 624-644. [CrossRef]

142. Coquenlorge, S.; Duchalais, E.; Chevalier, J.; Cossais, F.; Rolli-Derkinderen, M.; Neunlist, M. Modulation of lipopolysaccharide-induced neuronal response by activation of the enteric nervous system. J. Neuroinflamm. 2014, 11, 202. [CrossRef]

143. Maguire, M.; Maguire, G. Gut dysbiosis, leaky gut, and intestinal epithelial proliferation in neurological disorders: Towards the development of a new therapeutic using amino acids, prebiotics, probiotics, and postbiotics. Rev. Neurosci. 2019, 30, 179-201. [CrossRef]

144. Fiebich, B.L.; Batista, C.R.A.; Saliba, S.W.; Yousif, N.M.; de Oliveira, A.C.P. Role of Microglia TLRs in Neurodegeneration. Front. Cell. Neurosci. 2018, 12, 329. [CrossRef]

145. Wang, L.-M.; Wu, Q.; Kirk, R.A.; Horn, K.P.; Ebada Salem, A.H.; Hoffman, J.M.; Yap, J.T.; Sonnen, J.A.; Towner, R.A.; Bozza, F.A.; et al. Lipopolysaccharide endotoxemia induces amyloid- $\beta$ and p-tau formation in the rat brain. Am. J. Nucl. Med. Mol. Imaging 2018, 8, 86-99.

146. Zhan, X.; Stamova, B.; Sharp, F.R. Lipopolysaccharide Associates with Amyloid Plaques, Neurons and Oligodendrocytes in Alzheimer's Disease Brain: A Review. Front. Aging Neurosci. 2018, 10, 42. [CrossRef]

147. Sochocka, M.; Zwolińska, K.; Leszek, J. The Infectious Etiology of Alzheimer's Disease. Curr. Neuropharmacol. 2017, 15, 996-1009. [CrossRef]

148. Wang, X.-L.; Zeng, J.; Feng, J.; Tian, Y.-T.; Liu, Y.-J.; Qiu, M.; Yan, X.; Yang, Y.; Xiong, Y.; Zhang, Z.-H.; et al. Helicobacter pylori filtrate impairs spatial learning and memory in rats and increases $\beta$-amyloid by enhancing expression of presenilin-2. Front. Aging Neurosci. 2014, 6, 66. [CrossRef]

149. Pisa, D.; Alonso, R.; Rábano, A.; Rodal, I.; Carrasco, L. Different Brain Regions are Infected with Fungi in Alzheimer's Disease. Sci. Rep. 2015, 5, 15015. [CrossRef] [PubMed]

150. Pisa, D.; Alonso, R.; Fernández-Fernández, A.M.; Rábano, A.; Carrasco, L. Polymicrobial Infections In Brain Tissue From Alzheimer's Disease Patients. Sci. Rep. 2017, 7, 5559. [CrossRef]

151. Bittar, A.; Sengupta, U.; Kayed, R. Prospects for strain-specific immunotherapy in Alzheimer's disease and tauopathies. NPJ Vaccines 2018, 3, 9. [CrossRef] [PubMed]

152. Morgan, D. Immunotherapy for Alzheimer's Disease. J. Intern. Med. 2011, 269, 54-63. [CrossRef]

153. Cytokine Inhibition for Treatment of Alzheimer's Disease. Available online: http://www.medscape.com/ viewarticle/530141 (accessed on 28 August 2020).

154. Mengel, D.; Röskam, S.; Neff, F.; Balakrishnan, K.; Deuster, O.; Gold, M.; Oertel, W.H.; Bacher, M.; Bach, J.-P.; Dodel, R. Naturally occurring autoantibodies interfere with $\beta$-amyloid metabolism and improve cognition in a transgenic mouse model of Alzheimer's disease $24 \mathrm{~h}$ after single treatment. Transl. Psychiatry 2013, 3, e236. [CrossRef]

155. Rosenberg, R.N.; Fu, M.; Lambracht-Washington, D. Active full-length DNA A $\beta 42$ immunization in 3xTg-AD mice reduces not only amyloid deposition but also tau pathology. Alzheimer's Res. Ther. 2018, 10, 115. [CrossRef]

156. McAlpine, F.E.; Lee, J.-K.; Harms, A.S.; Ruhn, K.A.; Blurton-Jones, M.; Hong, J.; Das, P.; Golde, T.E.; LaFerla, F.M.; Oddo, S.; et al. Inhibition of soluble TNF signaling in a mouse model of Alzheimer's disease prevents pre-plaque amyloid-associated neuropathology. Neurobiol. Dis. 2009, 34, 163-177. [CrossRef]

157. Overk, C.; Masliah, E. Could changing the course of Alzheimer's disease pathology with immunotherapy prevent dementia? Brain 2019, 142, 1853-1855. [CrossRef]

158. Bostanciklioğlu, M. The role of gut microbiota in pathogenesis of Alzheimer's disease. J. Appl. Microbiol. 2019, 127, 954-967. [CrossRef]

159. Bonfili, L.; Cecarini, V.; Gogoi, O.; Berardi, S.; Scarpona, S.; Angeletti, M.; Rossi, G.; Eleuteri, A.M. Gut microbiota manipulation through probiotics oral administration restores glucose homeostasis in a mouse model of Alzheimer's disease. Neurobiol. Aging 2020, 87, 35-43. [CrossRef]

160. Hoffman, J.D.; Yanckello, L.M.; Chlipala, G.; Hammond, T.C.; McCulloch, S.D.; Parikh, I.; Sun, S.; Morganti, J.M.; Green, S.J.; Lin, A.-L. Dietary inulin alters the gut microbiome, enhances systemic metabolism and reduces neuroinflammation in an APOE4 mouse model. PLoS ONE 2019, 14, e0221828. [CrossRef] 
161. Tamtaji, O.R.; Heidari-Soureshjani, R.; Mirhosseini, N.; Kouchaki, E.; Bahmani, F.; Aghadavod, E.; Tajabadi-Ebrahimi, M.; Asemi, Z. Probiotic and selenium co-supplementation, and the effects on clinical, metabolic and genetic status in Alzheimer's disease: A randomized, double-blind, controlled trial. Clin. Nutr. 2019, 38, 2569-2575. [CrossRef]

162. Kobayashi, Y.; Kinoshita, T.; Matsumoto, A.; Yoshino, K.; Saito, I.; Xiao, J.-Z. Bifidobacterium Breve A1 Supplementation Improved Cognitive Decline in Older Adults with Mild Cognitive Impairment: An Open-Label, Single-Arm Study. J. Prev. Alzheimers Dis. 2019, 6, 70-75. [PubMed]

163. Hazan, S. Rapid improvement in Alzheimer's disease symptoms following fecal microbiota transplantation: A case report. J. Int. Med Res. 2020, 48, 030006052092593. [CrossRef]

164. Pistollato, F.; Battino, M. Role of plant-based diets in the prevention and regression of metabolic syndrome and neurodegenerative diseases. Trends Food Sci. Technol. 2014, 40, 62-81. [CrossRef]

165. Mariotti, F. Vegetarian and Plant-Based Diets in Health and Disease Prevention; Academic Press: Cambridge, MA, USA, 2017; ISBN 9780128039694.

166. Anastasiou, C.A.; Yannakoulia, M.; Kosmidis, M.H.; Dardiotis, E.; Hadjigeorgiou, G.M.; Sakka, P.; Arampatzi, X.; Bougea, A.; Labropoulos, I.; Scarmeas, N. Mediterranean diet and cognitive health: Initial results from the Hellenic Longitudinal Investigation of Ageing and Diet. PLoS ONE 2017, 12, e0182048. [CrossRef]

167. Pistollato, F.; Iglesias, R.C.; Ruiz, R.; Aparicio, S.; Crespo, J.; Lopez, L.D.; Manna, P.P.; Giampieri, F.; Battino, M. Nutritional patterns associated with the maintenance of neurocognitive functions and the risk of dementia and Alzheimer's disease: A focus on human studies. Pharmacol. Res. 2018, 131, 32-43. [CrossRef]

168. Scarmeas, N.; Stern, Y.; Mayeux, R.; Manly, J.J.; Schupf, N.; Luchsinger, J.A. Mediterranean diet and mild cognitive impairment. Arch. Neurol. 2009, 66, 216-225. [CrossRef]

169. Farooqui, T.; Farooqui, A.A. Role of the Mediterranean Diet in the Brain and Neurodegenerative Diseases; Academic Press: Cambridge, MA, USA, 2017; ISBN 9780128119600.

170. Tangney, C.C.; Li, H.; Wang, Y.; Barnes, L.; Schneider, J.A.; Bennett, D.A.; Morris, M.C. Relation of DASHand Mediterranean-like dietary patterns to cognitive decline in older persons. Neurology 2014, 83, 1410-1416. [CrossRef]

171. McEvoy, C.T.; Guyer, H.; Langa, K.M.; Yaffe, K. Neuroprotective Diets Are Associated with Better Cognitive Function: The Health and Retirement Study. J. Am. Geriatr. Soc. 2017, 65, 1857-1862. [CrossRef]

172. Terry, R.D.; Masliah, E.; Salmon, D.P.; Butters, N.; DeTeresa, R.; Hill, R.; Hansen, L.A.; Katzman, R. Physical basis of cognitive alterations in Alzheimer's disease: Synapse loss is the major correlate of cognitive impairment. Ann. Neurol. 1991, 30, 572-580. [CrossRef] [PubMed]

173. Cunnane, S.C.; Courchesne-Loyer, A.; St-Pierre, V.; Vandenberghe, C.; Pierotti, T.; Fortier, M.; Croteau, E.; Castellano, C.-A. Can ketones compensate for deteriorating brain glucose uptake during aging? Implications for the risk and treatment of Alzheimer's disease. Ann. N. Y. Acad. Sci. 2016, 1367, 12-20. [CrossRef]

174. Owen, O.E.; Morgan, A.P.; Kemp, H.G.; Sullivan, J.M.; Herrera, M.G.; Cahill, G.F., Jr. Brain metabolism during fasting. J. Clin. Investig. 1967, 46, 1589-1595. [CrossRef]

175. Castellano, C.-A.; Nugent, S.; Paquet, N.; Tremblay, S.; Bocti, C.; Lacombe, G.; Imbeault, H.; Turcotte, É.; Fulop, T.; Cunnane, S.C. Lower brain 18F-fluorodeoxyglucose uptake but normal 11C-acetoacetate metabolism in mild Alzheimer's disease dementia. J. Alzheimers. Dis. 2015, 43, 1343-1353. [CrossRef]

176. Ogawa, M.; Fukuyama, H.; Ouchi, Y.; Yamauchi, H.; Kimura, J. Altered energy metabolism in Alzheimer's disease. J. Neurol. Sci. 1996, 139, 78-82. [CrossRef]

177. Henderson, S.T. Ketone bodies as a therapeutic for Alzheimer's disease. Neurotherapeutics 2008, 5, 470-480. [CrossRef]

178. Kashiwaya, Y.; Bergman, C.; Lee, J.-H.; Wan, R.; King, M.T.; Mughal, M.R.; Okun, E.; Clarke, K.; Mattson, M.P.; Veech, R.L. A ketone ester diet exhibits anxiolytic and cognition-sparing properties, and lessens amyloid and tau pathologies in a mouse model of Alzheimer's disease. Neurobiol. Aging 2013, 34, 1530-1539. [CrossRef]

179. Włodarek, D. Role of Ketogenic Diets in Neurodegenerative Diseases (Alzheimer's Disease and Parkinson's Disease). Nutrients 2019, 11, 169. [CrossRef]

180. Murray, A.J.; Knight, N.S.; Cole, M.A.; Cochlin, L.E.; Carter, E.; Tchabanenko, K.; Pichulik, T.; Gulston, M.K.; Atherton, H.J.; Schroeder, M.A.; et al. Novel ketone diet enhances physical and cognitive performance. FASEB J. 2016, 30, 4021-4032. [CrossRef] 
181. Grammatikopoulou, M.G.; Goulis, D.G.; Gkiouras, K.; Theodoridis, X.; Gkouskou, K.K.; Evangeliou, A.; Dardiotis, E.; Bogdanos, D.P. To Keto or Not to Keto? A Systematic Review of Randomized Controlled Trials Assessing the Effects of Ketogenic Therapy on Alzheimer Disease. Adv. Nutr. 2020, nmaa073. [CrossRef]

182. Ma, D.; Wang, A.C.; Parikh, I.; Green, S.J.; Hoffman, J.D.; Chlipala, G.; Murphy, M.P.; Sokola, B.S.; Bauer, B.; Hartz, A.M.S.; et al. Ketogenic diet enhances neurovascular function with altered gut microbiome in young healthy mice. Sci. Rep. 2018, 8, 6670. [CrossRef]

183. Nagpal, R.; Neth, B.J.; Wang, S.; Craft, S.; Yadav, H. Modified Mediterranean-ketogenic diet modulates gut microbiome and short-chain fatty acids in association with Alzheimer's disease markers in subjects with mild cognitive impairment. EBioMedicine 2019, 47, 529-542. [CrossRef]

184. Neth, B.J.; Mintz, A.; Whitlow, C.; Jung, Y.; Solingapuram Sai, K.; Register, T.C.; Kellar, D.; Lockhart, S.N.; Hoscheidt, S.; Maldjian, J.; et al. Modified ketogenic diet is associated with improved cerebrospinal fluid biomarker profile, cerebral perfusion, and cerebral ketone body uptake in older adults at risk for Alzheimer's disease: A pilot study. Neurobiol. Aging 2020, 86, 54-63. [CrossRef]

185. Li, X.; Leonardi, I.; Semon, A.; Doron, I.; Gao, I.H.; Putzel, G.G.; Kim, Y.; Kabata, H.; Artis, D.; Fiers, W.D.; et al. Response to Fungal Dysbiosis by Gut-Resident CX3CR1 Mononuclear Phagocytes Aggravates Allergic Airway Disease. Cell Host Microbe 2018, 24, 847-856.e4. [CrossRef] [PubMed]

186. Yatsunenko, T.; Rey, F.E.; Manary, M.J.; Trehan, I.; Dominguez-Bello, M.G.; Contreras, M.; Magris, M.; Hidalgo, G.; Baldassano, R.N.; Anokhin, A.P.; et al. Human gut microbiome viewed across age and geography. Nature 2012, 486, 222-227. [CrossRef]

187. Rutayisire, E.; Huang, K.; Liu, Y.; Tao, F. The mode of delivery affects the diversity and colonization pattern of the gut microbiota during the first year of infants' life: A systematic review. BMC Gastroenterol. 2016, 16, 86. [CrossRef]

188. Moise, A.M.R. The Gut Microbiome: Exploring the Connection between Microbes, Diet, and Health; ABC-CLIO: Santa Barbara, CA, USA, 2017; ISBN 9781440842658.

189. Lach, G.; Schellekens, H.; Dinan, T.G.; Cryan, J.F. Anxiety, Depression, and the Microbiome: A Role for Gut Peptides. Neurotherapeutics 2018, 15, 36-59. [CrossRef]

190. Hasan, N.; Yang, H. Factors affecting the composition of the gut microbiota, and its modulation. PeerJ 2019, 7, e7502. [CrossRef]

191. Kim, C.H.; Park, J.; Kim, M. Gut Microbiota-Derived Short-Chain Fatty Acids, T Cells, and Inflammation. Immune Netw. 2014, 14, 277. [CrossRef]

Publisher's Note: MDPI stays neutral with regard to jurisdictional claims in published maps and institutional affiliations.

(C) 2020 by the authors. Licensee MDPI, Basel, Switzerland. This article is an open access article distributed under the terms and conditions of the Creative Commons Attribution (CC BY) license (http://creativecommons.org/licenses/by/4.0/). 